\title{
Decadal Variability of the Kuroshio Extension: Observations and an Eddy-Resolving Model Hindcast*
}

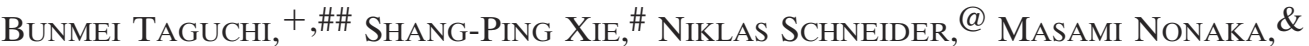 \\ Hideharu SASAKI, ** AND YoshiKaZU SASAI $\&$ \\ + Department of Meteorology, SOEST, University of Hawaii at Manoa, Honolulu, Hawaii \\ \# IPRC, and Department of Meteorology, SOEST, University of Hawaii at Manoa, Honolulu, Hawaii \\ @IPRC, and Department of Oceanography, SOEST, University of Hawaii at Manoa, Honolulu, Hawaii \\ \& Frontier Research Center for Global Change, JAMSTEC, Yokohama, Japan \\ ** Earth Simulator Center, JAMSTEC, Yokohama, Japan
}

(Manuscript received 20 June 2006, in final form 17 October 2006)

\section{ABSTRACT}

Low-frequency variability of the Kuroshio Extension (KE) is studied using observations and a multidecadal (1950-2003) hindcast by a high-resolution $\left(0.1^{\circ}\right)$, eddy-resolving, global ocean general circulation model for the Earth Simulator (OFES). In both the OFES hindcast and satellite altimeter observations, low-frequency sea surface height (SSH) variability in the North Pacific is high near the KE front. An empirical orthogonal function (EOF) analysis indicates that much of the SSH variability in the western North Pacific east of Japan is explained by two modes with meridional structures tightly trapped along the KE front. The first mode represents a southward shift and to a lesser degree, an acceleration of the KE jet associated with the 1976/77 shift in basin-scale winds. The second mode reflects quasi-decadal variations in the intensity of the KE jet. Both the spatial structure and time series of these modes derived from the hindcast are in close agreement with observations.

A linear Rossby wave model forced by observed wind successfully reproduces the time series of the leading OFES modes but fails to explain why their meridional structure is concentrated on the KE front and inconsistent with the broadscale wind forcing. Further analysis suggests that KE variability may be decomposed into broad- and frontal-scale components in the meridional direction-the former following the linear Rossby wave solution and the latter closely resembling ocean intrinsic modes derived from an OFES run forced by climatological winds. The following scenario is suggested for low-frequency KE variability: basin-scale wind variability excites broadscale Rossby waves, which propagate westward, triggering intrinsic modes of the KE jet and reorganizing SSH variability in space.

\section{Introduction}

The Kuroshio Extension (KE) is a swift eastward inertial jet formed after the Kuroshio separates from

\footnotetext{
* International Pacific Research Center Publication Number 432 and School for Ocean and Earth Science and Technology Publication Number 7099.
}

\footnotetext{
\#\# Current affliation: Earth Simulator Center, JAMSTEC, Yokohama, Japan.
}

Corresponding author address: Dr. Bunmei Taguchi, Earth Simulator Center, Japan Agency for Marine-Earth Science and Technology, 3173-25 Showa-machi, Kanazawa-ku, Yokohama, Kanagawa 236-0001, Japan.

E-mail: bunmei@jamstec.go.jp

DOI: $10.1175 / J C L I 4142.1$

(C) 2007 American Meteorological Society the Japanese coast at around $35^{\circ} \mathrm{N}, 142^{\circ} \mathrm{E}$. The $\mathrm{KE}$ region has the largest sea surface height $(\mathrm{SSH})$ variability on both mesoscale and interannual time scales in the extratropical North Pacific Ocean (Qiu 2002a). The Kuroshio-Oyashio Extension (KOE) region, including the $\mathrm{KE}$ and the Oyashio subarctic front, has recently been identified as the window in which subsurface ocean variability strongly affects sea surface temperature (SST; Xie et al. 2000). This subsurface feedback on SST occurs in winter when a deep mixed layer develops, by vertical entrainment (Schneider et al. 2002) or horizontal advection by the varying Kuroshio and Oyashio Extensions (Qiu 2000; Seager et al. 2001; Tomita et al. 2002; Scott and Qiu 2003). Thus, ocean dynamics are an important mechanism for low-frequency variability in SST, and possibly the overlying atmosphere via surface turbulent fluxes (Tanimoto et al. 
2003) in the KOE region. Coupled ocean-atmosphere model studies support this notion (Pierce et al. 2001; Schneider et al. 2002). In a multivariant regression analysis, Schneider and Cornuelle (2005) show that on decadal time scales KE intensity variability is an important contributor to the observed Pacific decadal oscillation (PDO) along with the Aleutian low and El NiñoSouthern Oscillation (ENSO). All these studies indicate the importance of understanding the mechanisms for decadal variability in upper-ocean dynamical fields such as SSH.

Two schools of thought exist with conflicting views regarding low-frequency variations of upper-ocean circulation. The first school points to the large internal variability in double-gyre circulation simulated in simple idealized models forced by steady wind forcing (Jiang et al. 1995; Dijkstra and Ghil 2005). This view appears consistent with snapshot satellite images of SST and SSH, which show a turbulent and chaotic KOE. The recirculation and narrow western boundary current extension themselves are generally considered as resulting from the eastward advection of potential vorticity anomalies from the western boundary layer (Cessi et al. 1987). The nonlinear interaction of recirculation, PV advection, and eddies cause the doublegyre circulation to vacillate between a straight and penetrative inertial jet and a meandering and westward confined one (e.g., McCalpin and Haidvogel 1996). Using a three-layer quasigeostrophic model, Dewar (2003) and Hogg et al. (2005) identify a low-frequency $(>10$ yr) mode of intrinsic variability characterized by shifts in the inertial jet position and slow adjustment in potential vorticity. They consider this mode as being distinct from the linear Rossby wave adjustment. The second school of thought views the $\mathrm{KOE}$ variability as deterministic and consistent with the linear baroclinic Rossby wave adjustment to wind variability. Analyzing historical observations of subsurface temperature, Deser et al. (1999) detected westward-intensified structures in decadal changes associated with the 1976/77 climate regime shift, which they suggested are due to the Sverdrup adjustment to basin-scale wind changes. This result was confirmed by ocean general circulation model (OGCM) studies (Miller et al. 1998; Xie et al. 2000; Seager et al. 2001). Indeed, the slow westward propagation of wind-forced baroclinic Rossby waves has been exploited for skillful prediction of ocean pressure variability in the KOE region with a lead time up to a year (Schneider and Miller 2001).

While the school of wind-forced Rossby waves has been successful in explaining broadscale $(>1000 \mathrm{~km})$ subsurface anomalies, most of observational and OGCM studies on low-frequency variability in the North Pacific
Ocean circulation are limited by the coarse resolution of their data/models that does not resolve the oceanic fronts and recirculations. It remains to be seen whether the same success can be extended to studying the variability of the inertial KE jet and the Kuroshio recirculation, both highly nonlinear phenomena full of internal variability.

Opportunities are emerging to study low-frequency variability of the narrow KE jet owing to the accumulation of satellite altimeter observations and a recent multidecadal, eddy-resolving $\left(0.1^{\circ}\right.$ horizontal resolution) OGCM hindcast performed on Japan's Earth Simulator supercomputer. From 11-yr-long satellite SSH data, Qiu (2003) found decadal modulations in the KE jet's intensity. Analyzing the Earth Simulator hindcast, Nonaka et al. (2006) showed that the well-known basinwide cooling during the early 1980s is accompanied by the southward shift and intensification of two separate oceanic fronts: the KE and the subarctic Oyashio fronts. Although Nonaka et al. (2006) attributed the cooling along the KE to linear Rossby wave adjustment, the relevant dynamics and other possible modes of variability were not fully explored.

The present study uses satellite SSH observations and the Earth Simulator hindcast to study decadal variability of the KE jet and the recirculation to the south. In particular, we are interested in what determines the spatiotemporal structure of this variability. Specific questions to be addressed include the following: How well does the high-resolution model hindcast capture the observed variability in the KE jet? How is the ocean variability related to atmospheric wind forcing? What are the role and contribution of oceanic intrinsic nonlinearity to this variability? We will show that the model hindcast is remarkably consistent with satellite and other in situ observations. With its realism established, the model hindcast offers a powerful tool to study the nature and mechanism of ocean variability prior to the satellite altimetry era. Our analysis shows that while the linear Rossby wave theory explains the temporal variability, nonlinear ocean dynamics play an essential role in organizing the spatial structure, thereby reconciling two conflicting schools of thought reviewed above. The present study will rely mostly on empirical analysis to derive the spatiotemporal structure and relate it to wind forcing; thus, important information for future studies to further decipher the underlying mechanisms and dynamics.

The rest of the paper is organized as follows. Section 2 describes models and observational data used in this study. Section 3 examines the spatiotemporal structure of low-frequency variability in the $\mathrm{KE}$ and recirculation while section 4 studies the processes that determine this 
structure. Section 5 discusses our results in light of previous modeling studies and their implications while section 6 is a summary.

\section{Model output and observational data}

\section{a. Eddy-resolving model}

We analyze a multidecadal hindcast by the OGCM for the Earth Simulator (OFES; Masumoto et al. 2004; Nonaka et al. 2006; Sasaki and Nonaka 2006). The OFES is based on the Third Modular Ocean Model (MOM3; Pacanowski and Griffies 1999) and has been substantially modified for optimal performance on the Earth Simulator. The model covers a near-global domain extending from $75^{\circ} \mathrm{S}$ to $75^{\circ} \mathrm{N}$, with a horizontal resolution of $0.1^{\circ}$ and 54 vertical levels. It is forced by surface wind stress, heat, and freshwater fluxes derived from the daily-mean National Centers for Environmental Prediction-National Center for Atmospheric Research (NCEP-NCAR) reanalysis (Kalnay et al. 1996). Surface turbulent heat flux is calculated using the model SST and meteorological variables from the NCEP-NCAR atmospheric reanalysis while sea surface salinity is restored to the observed monthly climatology. Within $3^{\circ}$ from the model's southern and northern boundaries at $75^{\circ} \mathrm{S}$ to $75^{\circ} \mathrm{N}$, temperature and salinity are restored to the monthly climatology of the World Ocean Atlas 1998 (WOA98; Boyer et al. 1998a,b,c). From an initial condition at rest with observed (WOA98) annual-mean temperature and salinity, the model was first spun up for $50 \mathrm{yr}$ with monthly climatological atmospheric forcing, followed by a 54-yr hindcast integration forced with the daily-mean reanalysis data from 1950 to 2003 (hindcast run). This is the first multidecadal hindcast that resolves fronts and eddies from the Tropics to the midlatitude in the World Ocean, providing a unique opportunity to study interannul to decadal variability of narrow western boundary currents and their eastward extensions. Nonaka et al. (2006), for example, show that the shift around the early 1980s in the northwestern Pacific east of Japan displays distinct vertical structures along the KE and Oyashio fronts, with deep subsurface anomalies in the former and large SST anomalies in the latter regions, respectively. In this study, we analyze the hindcast run for a 42-yr period from 1962 to 2003, regarding the first $12 \mathrm{yr}$ of the hindcast as the spinup, during which the model adjusts to changes in atmospheric forcing from climatological to 1950 values. All our analysis uses a subsampled output on a $0.5^{\circ}$ grid to reduce the data size.

In addition to the hindcast run, two runs forced with monthly climatological atmospheric forcings are carried out: a climatological control run that continues the spinup for another $48 \mathrm{yr}$ (Sasai et al. 2004), and a prediction $^{1}$ run initialized with the hindcast run on 1 January 2000 and integrated forward for another $3 \mathrm{yr}$.

\section{b. Observational data}

The OFES hindcast is compared to the following observational data. We use SSH anomaly maps compiled from the Ocean Topography Experiment (TOPEX)/ Poseidon (T/P), Jason, and the European Remote Sensing satellite $(E R S-1 / 2)$ altimeter observations, distributed by the Archiving, Validation and Interpretation of Satellite Oceanographic Data (AVISO; Ducet et al. 2000). The data are mapped on the Mercator grid with $1 / 3^{\circ}$ resolution in longitude and varying spacing in latitude (from $37 \mathrm{~km}$ at the equator to $18.5 \mathrm{~km}$ at $60^{\circ} \mathrm{N}$ ). Monthly mean maps are used, calculated from the original weekly mean data that cover an 11-yr period from January 1993 to December 2003.

To validate the OFES hindcast prior to the satellite altimeter era, we use the monthly ocean temperature data compiled from expendable bathythermograph (XBT) observations at the Joint Environmental Data Analysis Center of the Scripps Institution of Oceanography (White 1995). For the period during1955-2004, the XBT observations are optimally interpolated on a $2^{\circ}$ latitude by $5^{\circ}$ longitude grid with $2.5^{\circ}$ latitude by $5^{\circ}$ longitude decorrelation scales.

\section{Modes of KE variability}

This section examines the dominant modes of KE variability and compares them with satellite and in situ observations. In particular, we investigate the effect of the sharp KE jet on the modal structure and how these modes are related to variability in the recirculation.

\section{a. Variance}

Figure 1 compares the standard deviation of interannual SSH variations. For both the hindcast and T/P observations, the calculation of the standard deviation is based on monthly anomalies defined as deviations from the 11-yr (1993-2003) monthly climatology. A 12month low-pass filter is applied to suppress mesoscale eddies. Also shown in contours are the absolute mean SSH fields from the hindcast and the estimate of Niiler et al. (2003) using surface drifter and satellite altimeter observations. The OFES hindcast captures the salient

\footnotetext{
${ }^{1}$ The term "prediction" is used in the sense that no interannual history in the surface wind and buoyancy forcing is provided to the model during the additional 3-yr integration after 2000 .
} 

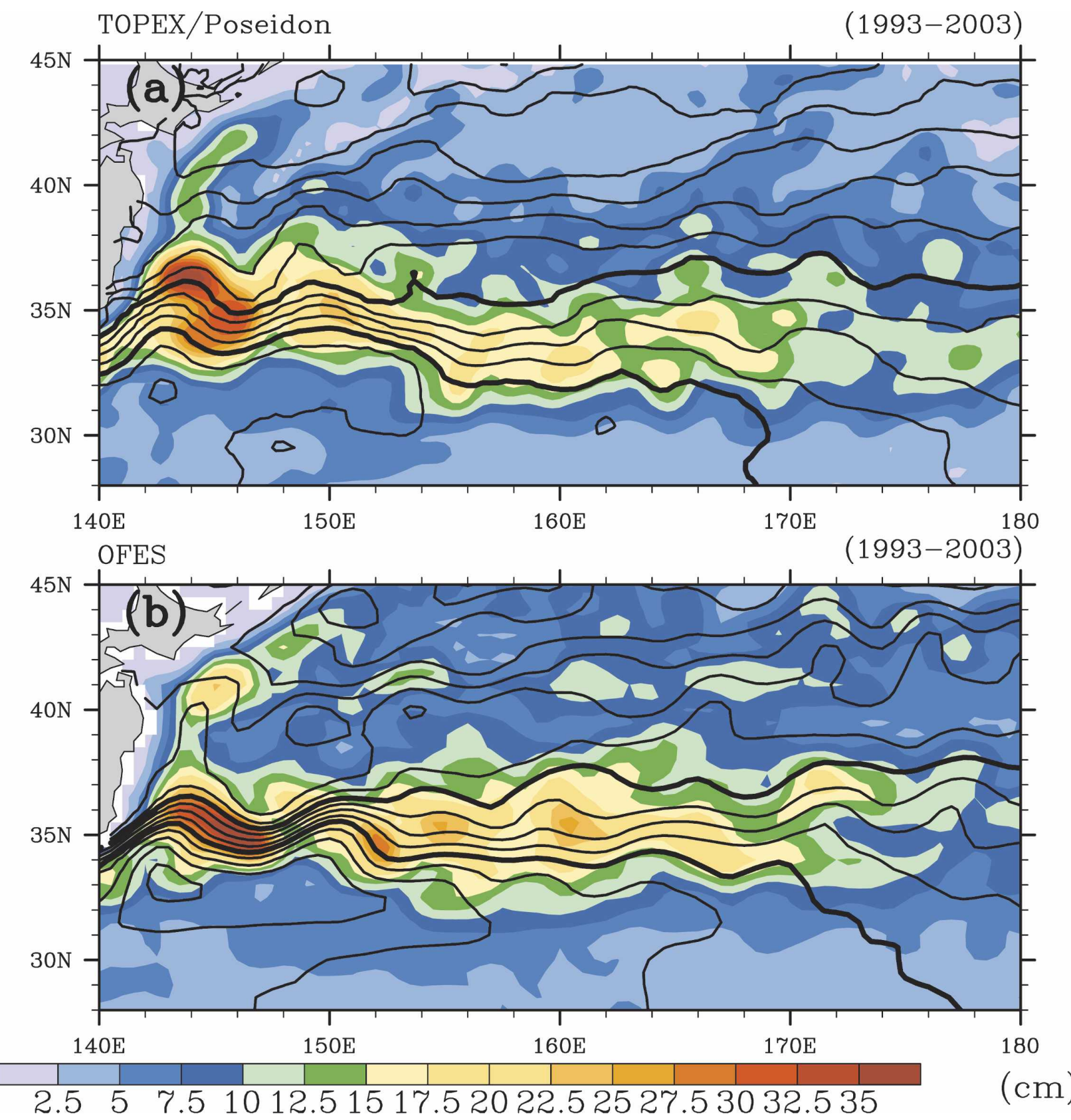

FIG. 1. (a) Standard deviation of 12-month low-pass-filtered SSH observed by satellite altimeters (shaded) and the mean absolute sea level (contours at $10-\mathrm{cm}$ intervals; the 60 - and $100-\mathrm{cm}$ contours thickened to delineate the KE frontal zone). (b) Same as in (a), but for the OFES hindcast (the 30- and 70-cm contours for the mean SSH are thickened).

features of both the mean and interannual variance of observed SSH. In the mean SSH field, the KOE, depicted as a broad eastward current in coarse-resolution $\left(1^{\circ}\right.$ or less) models, consists of two distinct fronts of the $\mathrm{KE}$ and Oyashio Currents. Qu et al. (2002) note such a separation of the KOE into two distinct narrow jets in a $0.25^{\circ}$ OGCM. In both the OFES and observations, a sharp KE front is found nearly zonally at around $34^{\circ}-$ $35^{\circ} \mathrm{N}$ with quasi-stationary meanders east of Japan in the upstream $\mathrm{KE}$ at $141^{\circ}-150^{\circ} \mathrm{E}$. High interannual variance is concentrated within a narrow latitudinal band along the mean $\mathrm{KE}$ front. Specifically, west of $170^{\circ} \mathrm{E}$, the standard deviation exceeds $20 \mathrm{~cm}$ within a frontal band, over which the mean SSH drops $40 \mathrm{~cm}$ (delineated by two thick contour lines in Fig. 1), while in most of the area outside the band, the standard deviation is 
less than $10 \mathrm{~cm}$. In the OFES, there is a band of secondary maximum in SSH variance along the Oyashio front around $41^{\circ} \mathrm{N}$, which is not obvious in the $\mathrm{T} / \mathrm{P}$ observations.

Despite the good agreement of the slow frontal variability between the OFES hindcast and altimeter observations, there are also significant discrepancies. In the observations, the KE front shifts southward by $1^{\circ}-$ $1.5^{\circ}$ around $152^{\circ}-154^{\circ} \mathrm{E}$ east of the KE's second stationary meander, and is associated with a southward displacement of the interannnual variance. The hindcast SSH does not show this meridional shift of the mean front and its variability. Nevertheless, the overall agreement of the mean and interannual variance with observations encourages us to look further into the simulated variability.

\section{b. Leading mode and comparison with satellite altimetry}

Now we examine the spatial and temporal structures of the KE's low-frequency variations. Since both the mean and variance fields of SSH are zonally enlongated, we focus on the meridional structure of the KE variability by zonally averaging variables in $142^{\circ} \mathrm{E}-$ $180^{\circ}{ }^{2}$ The zonal averaging suppresses mesoscale variability while emphasizing low-frequency variability. We apply the empirical orthogonal function (EOF) analysis to the zonal mean in a latitudinal domain $30^{\circ}-45^{\circ} \mathrm{N}$ so that the EOF patterns and the associated principal components (PCs) represent the spatial and temporal variations, respectively. The EOF analysis is applied independently to the hindcast and observations, and the results are then compared.

Satellite altimeters, with high meridional resolution, provide an unprecedented opportunity to observe the meridional structure of SSH variability and validate model simulations. Figure 2 compares the first EOF mode between the OFES and the altimeter analyzed from 1993 to 2003. The OFES hindcast successfully captures the observed EOF-1, both with large loading concentrated near the KE jet. The model EOF peaks more sharply around the mean KE jet than in observations, reflecting the more zonal KE jet in the OFES simulation than in the altimeter observation as mentioned in section 3a. Dependence of the EOF-1 pattern

\footnotetext{
${ }^{2}$ Although the KE's mean frontal structure and interannual variability are not exactly uniform in the zonal direction within this sector, we first highlight the meridional structure of the KE frontal variability representative of the whole KOE region ranging from the Japanese coast to the date line. The dependence of the meridional structure of the variability on the choice of the zonal sector is discussed in section $3 \mathrm{c}$.
}

on the mean flow structure is discussed in section $3 \mathrm{c}$. Zonal current anomalies at $100 \mathrm{~m}$ associated with the EOF-1 of simulated SSH represent a northward shift of the KE jet (Figs. 2b,c), with the acceleration to the north of the jet slightly larger than the deceleration to the south.

The first EOF mode explains about $50 \%$ of the zonal-mean SSH variability within $30^{\circ}-45^{\circ} \mathrm{N}$ in both observations and the OFES hindcast. The hindcast PC-1 tracks the observations remarkably well, and both show a full decadal cycle. This close agreement with observations demonstrates the skills of the eddy-resolving OFES hindcast in simulating the low-frequency variability of the narrow inertial $\mathrm{KE}$ jet. In particular, the hindcast captures the following KE variability documented in Qiu and Chen (2005): the gradual weakening and southward shift of the KE jet from 1993 to 1996, and the steady strengthening and northward migration of the jet after 1997.

\section{c. The KE jet's signature in modal structure}

The strong trapping of SSH variance and the first EOF pattern by the KE jet suggests that the mean jet exerts a strong influence on the meridional pattern of ocean variability. To corroborate this point, we take advantage of the zonal variations of the mean $\mathrm{KE}$ front in the altimeter observation and divide the $\mathrm{KE}$ region into three $10^{\circ}$-wide longitudinal sectors at $142^{\circ}-152^{\circ} \mathrm{E}$, $156^{\circ}-166^{\circ} \mathrm{E}$, and $170^{\circ} \mathrm{E}-180^{\circ}$. The observed $\mathrm{KE}$ front varies its meridional structure significantly among these longitudinal sectors. In the upstream sector the sharp $\mathrm{KE}$ front is located around $34.5^{\circ} \mathrm{N}$ but shifts to around $33^{\circ} \mathrm{N}$ in the middle sector, and there is no distinct front in the downstream sector (Fig. 3, upper left). We calculate the meridional EOF modes of the T/P SSH within $30^{\circ}-45^{\circ} \mathrm{N}$ separately for each longitudinal sector. The meridional pattern of the first mode (Fig. 3, upper right) displays a clear dependency on the mean flow, with its peak tracking the KE front as the latter shifts southward from the upstream to the middle sector. The EOF shows a much broader pattern in the downstream sector where the mean flow broadens in the meridional direction without a sharply defined front in SSH.

We further calculate the two-dimensional EOF for the observed SSH variability in a domain of $140^{\circ} \mathrm{E}-180^{\circ}$ and $30^{\circ}-45^{\circ} \mathrm{N}$ and show the first mode in color shaded in the upper-left panel of Fig. 3. The leading EOF explains $34 \%$ of the total variance, with large loading over or near the mean $\mathrm{KE}$ front west of $170^{\circ} \mathrm{E}$, consistent with the one-dimensional EOF modes over $30^{\circ}-45^{\circ} \mathrm{N}$. Near the date line, the mean eastward flow broadens, and so does the positive loading in the two-dimensional 

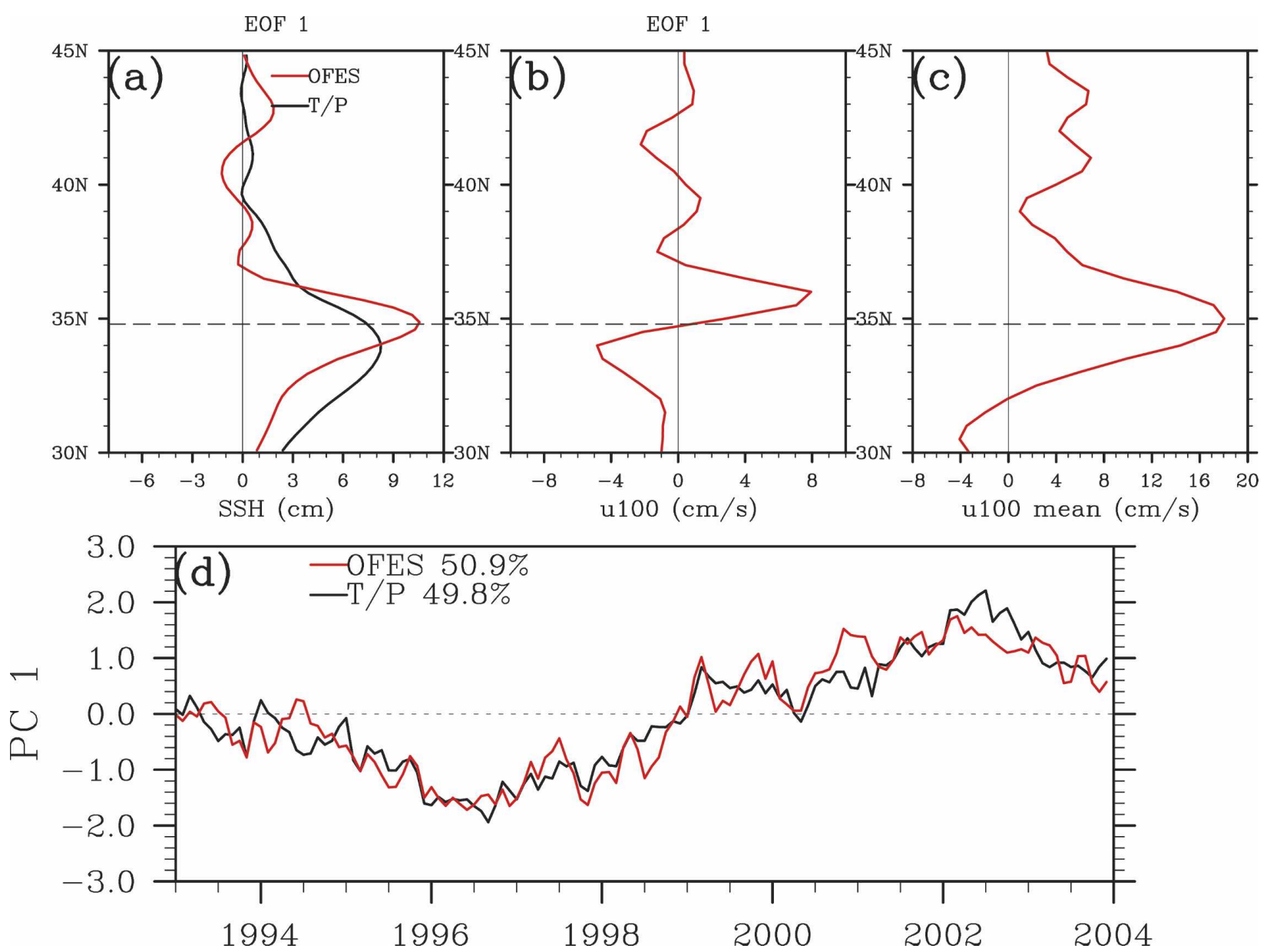

FIG. 2. (a) EOF-1 and (d) PC-1 of zonal and monthly mean SSH anomalies (cm) for the period 1993-2003: the OFES hindcast (red curve) and satellite altimeter observations (black). (b) Zonal current velocity at $100-\mathrm{m}$ depth $\left(\mathrm{cm} \mathrm{s}^{-1}\right)$ projected onto the SSH PC-1 in the OFES hindcast. (c) OFES climatology of zonal current velocity at 100-m depth.

EOF. Section 4 discusses more about the interaction of the mean flow and wind-induced variability.

\section{d. Multidecadal analysis}

The rest of the paper analyzes the longer 42-yr record from the hindcast for 1962-2003. The EOF analysis is applied to the zonal-mean SSH anomalies averaged over $142^{\circ} \mathrm{E}-180^{\circ}$ within $30^{\circ}-45^{\circ} \mathrm{N}$ (the same way as described in section $3 \mathrm{~b}$ ). The first two EOFs account for $67 \%$ of the total variance. The two modes are distinct not only in spatial pattern but also in explained variance (44\% versus $24 \%$ ). The first mode (Fig. 4a, black curve) explains $43.8 \%$ of total variance, and displays a meridional profile with a single peak in SSH (Fig. 4a) and a dipole in the zonal current centered around $35.8^{\circ} \mathrm{N}$ (Fig. 4b, black curve), where the mean KE jet is located (Fig. 4c). Thus, the first mode primarily represents the north-south shift of the KE jet. Indeed the time series of the PC-1 corresponds well with the zonal mean of the KE's latitudinal position determined as the maximum $u$ velocity at $100 \mathrm{~m}$ (Fig. 4d, correlation coefficient $=0.61$ ). This mode also exhibits an intensification of the KE jet (with its southward migration) as the zonal current dipole is not symmetric about the mean KE position, with a stronger southern pole.

Extending the analysis period beyond the satellite altimeter era, Fig. 5 compares the OFES hindcast with the XBT-based subsurface temperature dataset of White (1995). We use the temperature data at 400-m depth, which cuts through the upper thermocline in the KE region (e.g., Fig. 9 of Nonaka et al. 2006). To focus on interannual to decadal time scales, the annual mean data are used for the EOF analysis, which increases the explained variance to $60 \%$ in OFES. PC- 1 derived from the model and the XBT observations are in good agreement, with a correlation coefficient of 0.74 , both displaying a distinct decline as much as three standard deviations in PC-1 during the early 1980s (Fig. 5b). This 
EOF $1 \mathrm{~T} / \mathrm{P}$

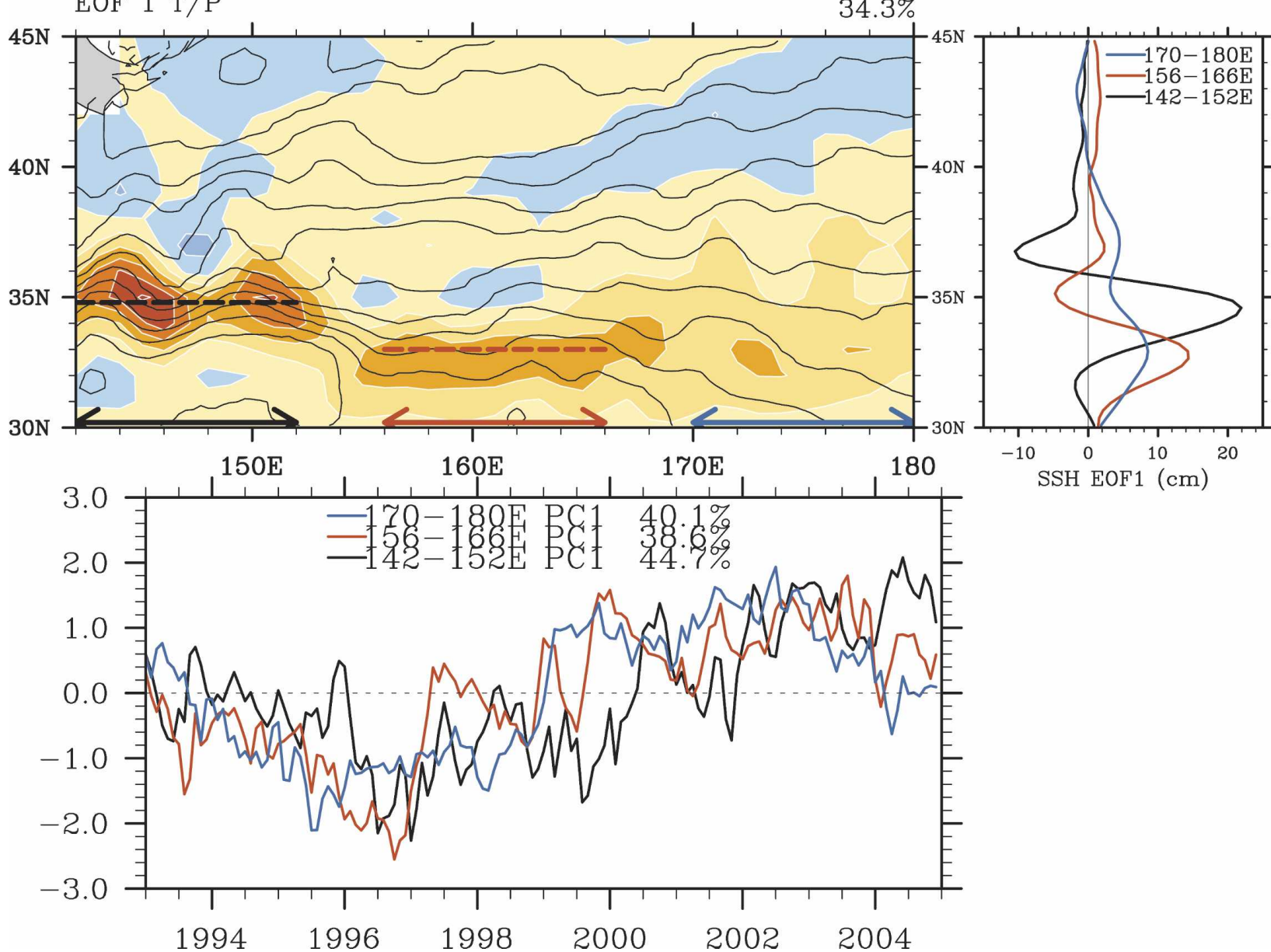

FIG. 3. (top left) Two-dimensional EOF-1 (shaded) of monthly mean T/P SSH, superposed with the mean SSH contours with the three zonal bands defined in arrows at bottom. (top right) EOF-1 and (bottom) PC-1 of monthly and zonal-mean SSH for each zonal band.

decline is likely a delayed response to the wind change associated with the 1976/77 regime shift (Miller et al. 1994; Trenberth and Hurrell 1994), for which section 4 discusses the mechanism. The large discrepancy in PC-1 between the XBT observation and OFES hindcast around 1991 is due to a sudden warming more than $1^{\circ} \mathrm{C}$ at $400-\mathrm{m}$ depth that occupied a wide area of the $\mathrm{KOE}$ region in observations, but is not obvious in the hindcast. The cause of this warming in observation is not known. As might be expected from the low meridional resolution of the XBT dataset, the observed EOF-1 displays a smoother meridional profile with a broad peak in $34^{\circ}-36^{\circ} \mathrm{N}$, but is otherwise in broad agreement with the OFES hindcast.

The second mode of SSH variability accounts for $23.5 \%$ variance, and represents an intensification of the $\mathrm{KE}$ jet, with a peak in the zonal current at the latitude of the mean jet (Fig. 4b, red curve). The PC-2 tracks very well the SSH difference between $34.5^{\circ}$ and $37^{\circ} \mathrm{N}$
(Fig. 4e, correlation coefficient $=0.71$ ), the latitudinal band for the KE jet core. Unlike the PC-1 that is characterized by a jump in the early 1980s, the PC-2 displays quasi-regular oscillations with a period of 10-15 yr.

The order of EOF modes may be sensitive to the choice of analysis period. The EOF-1 for the T/P era (1993-2003; $\left.\mathrm{EOF}_{\mathrm{TP}}-1\right)$ resembles the second more than the first EOF mode from the multidecadal (1962-2003) analysis $\left(\mathrm{EOF}_{\mathrm{MD}}\right)$. The first $\mathrm{EOF}_{\mathrm{TP}}$ and second $\mathrm{EOF}_{\mathrm{MD}}$ both peak in $34^{\circ}-35^{\circ} \mathrm{N}$, unlike the first $\mathrm{EOF}_{\mathrm{MD}}$, which reverses sign at $34^{\circ} \mathrm{N}$. This is consistent with the fact that the $\mathrm{T} / \mathrm{P}$ era is dominated by $\mathrm{PC}_{\mathrm{MD}}-2$ with little variability in $\mathrm{PC}_{\mathrm{MD}}-1$ (Fig. 4). The $\mathrm{EOF}_{\mathrm{TP}}$ still mainly represents a north-south shift in the KE jet, which is located $1^{\circ}$ south of the 1962-2003 mean jet during the $\mathrm{T} / \mathrm{P}$ era. The change in the order of EOF modes illustrates the difficulty in physical interpretation of EOF modes of inertial jet variability as discussed in Fyfe and Lorenz (2005). 

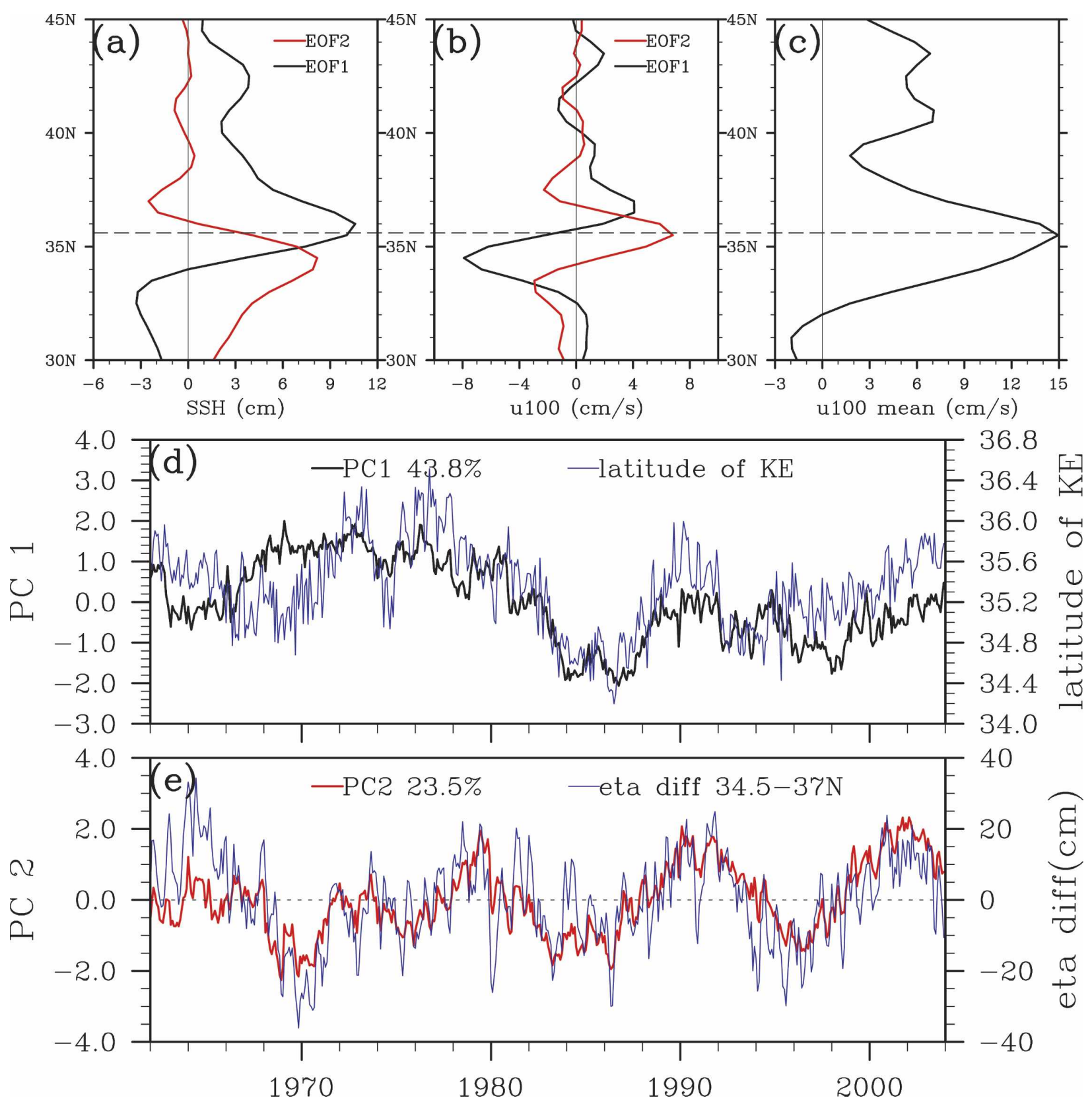

FIG. 4. (a) The leading two EOFs of zonal and monthly mean SSH anomalies (cm) for the OFES multidecadal (1962-2003) hindcast. Black (red) curve represents the first (second) mode. (b) Zonal current velocity at $100-\mathrm{m} \mathrm{depth}\left(\mathrm{cm} \mathrm{s}^{-1}\right.$ ) projected onto the SSH PCs in the OFES hindcast. (c) OFES climatology of zonal current velocity at 100-m depth for the period 1962-2003. (d) PC-1 (normalized to unit standard deviation, black curve) and zonal-mean of the KE latitude (blue) in the OFES hindcast. (e) PC-2 (red) and SSH difference between $34.5^{\circ}$ and $37^{\circ} \mathrm{N}$ (blue).

\section{e. Recirculation variability}

Analyzing satellite altimeter data, Qiu and Chen (2005) quantified the close connection in low-frequency variability between the upstream $\mathrm{KE}$ and the recirculation to the south. Since the two meridional modes described in section $3 \mathrm{~d}$ involve the KE's meridional shift and intensification, it is of interest to compare the
OFES and the altimeter data in terms of recirculation gyre variability. The EOF modes used in this section are those for the 1962-2003 period.

Following Qiu and Chen (2005), the KE recirculation strength is defined by

$$
S(t)=\iint{ }_{A} h(x, y, t) d x d y,
$$



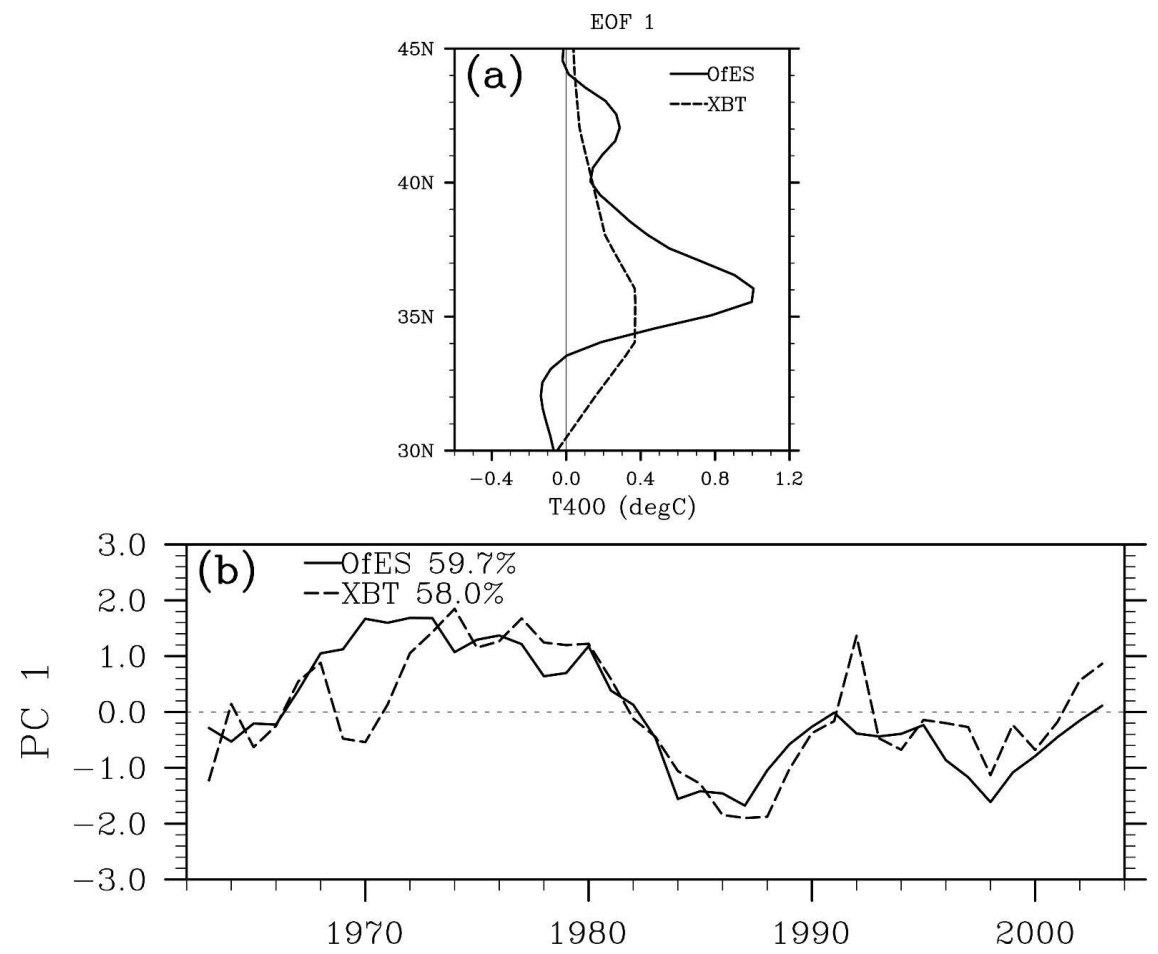

FIG. 5. Comparison of the annual- and zonal-mean temperature at 400-m depth between OFES (solid lines) and XBT observations (dashed lines): (a) EOF-1 and (b) PC-1.

where $h(x, y, t)$ is the monthly absolute $\mathrm{SSH}$ and $A$ denotes the area within which the $\mathrm{SSH}$ value exceeds a threshold $h_{0}$ in the upstream KE region $\left(30^{\circ}-37^{\circ} \mathrm{N}\right.$, $\left.141^{\circ}-158^{\circ} \mathrm{E}\right)$. A value $h_{0}$ is chosen to be $90(110) \mathrm{cm}$ for the OFES (the altimeter), whose contour line defines the outer boundary of the recirculation well. Choice of the specific values of $h_{0}$ between 90 and $100 \mathrm{~cm}$ hardly affect the following result. As shown in Fig. 6a, the recirculation strength in the OFES hindcast and the altimeter observation corresponds very well with each other, with the former also closely following the time series of the PC-2. This indicates OFES's ability to simulate realistically the modulation of the KE's recirculation strength and the jet intensification.

We also compare the recirculation position defined by the weighted average of the latitudinal center of the recirculation $y$ (Qiu and Chen 2005):

$$
y_{C}(t)=\frac{1}{S(t)} \iint{ }_{A} y h(x, y, t) d x d y
$$

The time series of the recirculation position simulated by the OFES closely follows the model PC-1, which mainly represents the north-south shift of the KE (Fig. $6 b)$. While systematically displaced south compared to observations by $0.2^{\circ}-0.5^{\circ}$, the simulated recirculation position displays a sharp northward shift around in 1999, in agreement with altimeter observations.

\section{Processes}

This section discusses processes and mechanisms that determine the spatiotemporal structure of the KE's meridional modes. In particular, we focus on linear baroclinic Rossby waves and nonlinear intrinsic variability of the KE front and the recirculation.

\section{a. Baroclinic Rossby wave}

As reviewed in section 1, linear baroclinic Rossby wave adjustment is a widely used concept to explain the dynamical response of the ocean to wind changes, with significant skills in hindcasting decadal anomalies of the thermocline depth in the broad KOE region (Schneider and Miller 2001), and decadal variability in the KE jet (Qiu 2003) and the recirculation gyre to the south (Qiu and Chen 2005). We examine to what extent a linear Rossby wave model can reproduce the fully nonlinear OFES hindcast.

We adopt the linear vorticity equation for the first baroclinic mode under the longwave approximation:

$$
\frac{\partial h}{\partial t}-c_{R} \frac{\partial h}{\partial x}=-\frac{g^{\prime}}{g} w_{e}-\varepsilon h,
$$


(a) $\mathrm{KE}$ recirculation strength

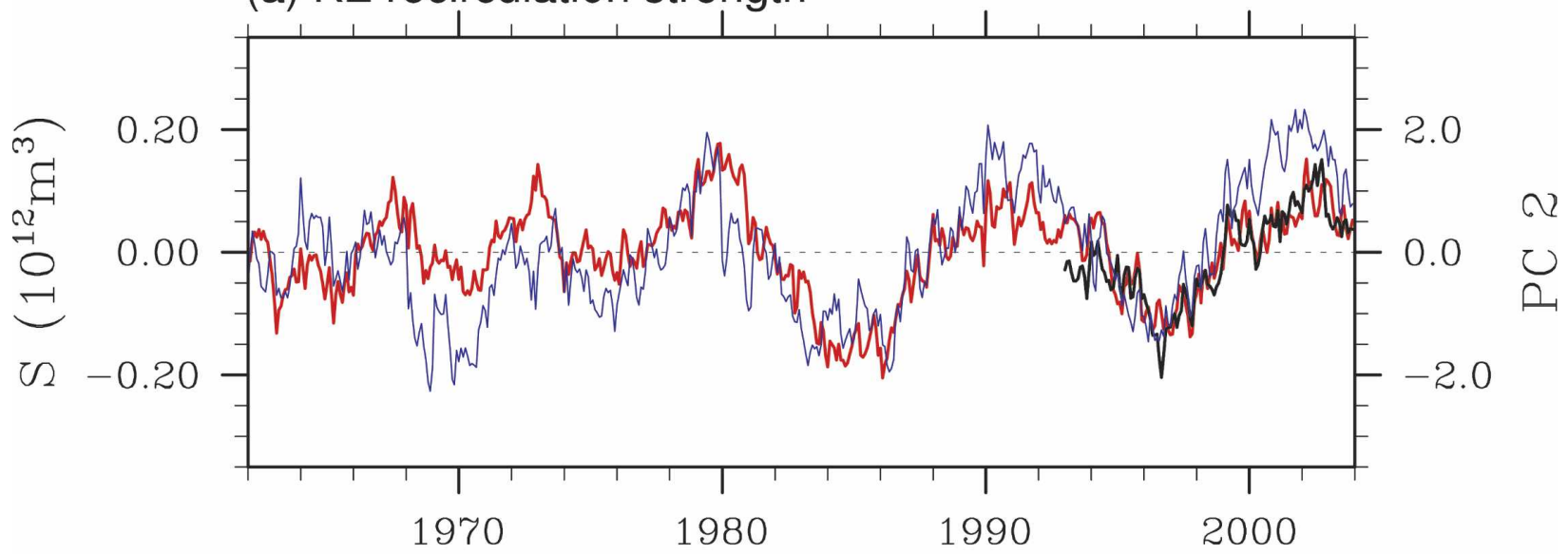

(b) KE recirculation position

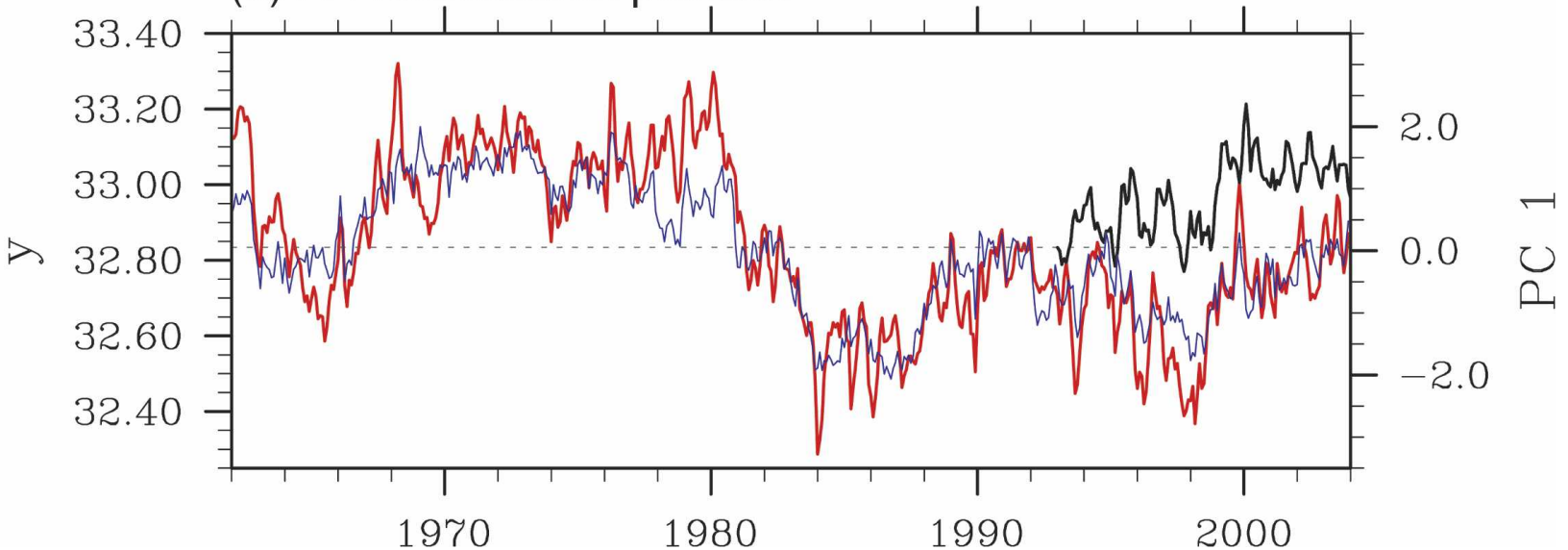

FIG. 6. (a) KE recirculation strength (OFES in red and altimeter in black) defined by Eq. (1), and PC-2 of OFES SSH anomalies (blue). (b) Same as in (a), but for the recirculation position defined by Eq. (2) and OFES PC-1.

where $h$ is baroclinic component of the $\mathrm{SSH}, c_{\mathrm{R}}$ the zonal phase speed of the long baroclinic Rossby wave, $g$ the gravity, $g^{\prime}$ the reduced gravity, $w_{e}=\operatorname{curl}\left(\tau / f \rho_{0}\right)$ is the Ekman pumping velocity, $\rho_{0}$ the density, $f$ the Coriolis parameter, $\tau$ the wind stress vector, and $\varepsilon$ the Newtonian damping coefficient. A formal derivation of Eq. (3) and its solution can be found in Qiu (2002b), who also showed the necessity to include the dissipation to match the solution to observations. The solution to this equation yields

$h(x, t)=\frac{g^{\prime}}{g c_{\mathrm{R}}} \int_{x_{e}}^{x} w_{e}\left(x^{\prime}, t+\frac{x-x^{\prime}}{c_{\mathrm{R}}}\right) \exp \left[\frac{\varepsilon}{c_{\mathrm{R}}}\left(x-x^{\prime}\right)\right] d x^{\prime}$,

where we ignore the SSH signal emanated from the eastern boundary $\left(x=x_{e}\right)$. With this solution and the phase speed $c_{\mathrm{R}}$ estimated from the OFES hindcast, we compute SSH by integrating the Ekman pumping forc- ing $w_{e}$ computed from the NCEP-NCAR monthly wind stress data, along the Rossby wave characteristics at latitudes (about every $1.9^{\circ}$ ) on the Gaussian grid of the NCEP-NCAR reanalysis. We then derive the EOF modes of linear model SSH anomalies zonally averaged at $142^{\circ} \mathrm{E}-180^{\circ}$ within the latitudinal range of $30^{\circ}-45^{\circ} \mathrm{N}$ the same way as in section 3 for the OFES and observations.

The meridional modes for the linear Rossby wave model hindcast are shown in Fig. 7 together with the OFES modes (black curves). The linear Rossby wave model captures the temporal evolution of the OFES's leading modes very well (Figs. 7c,d) except a 1-2-yr phase lag behind the OFES PC-2, a discrepancy especially clear during 1990s. The exact reason of this phase lag is not known but uncertainties of phase speed estimate could be one reason. The meridional structure of the Rossby wave solution, however, is quite different from that of the OFES hindcast (Figs. 7a,b). While the 

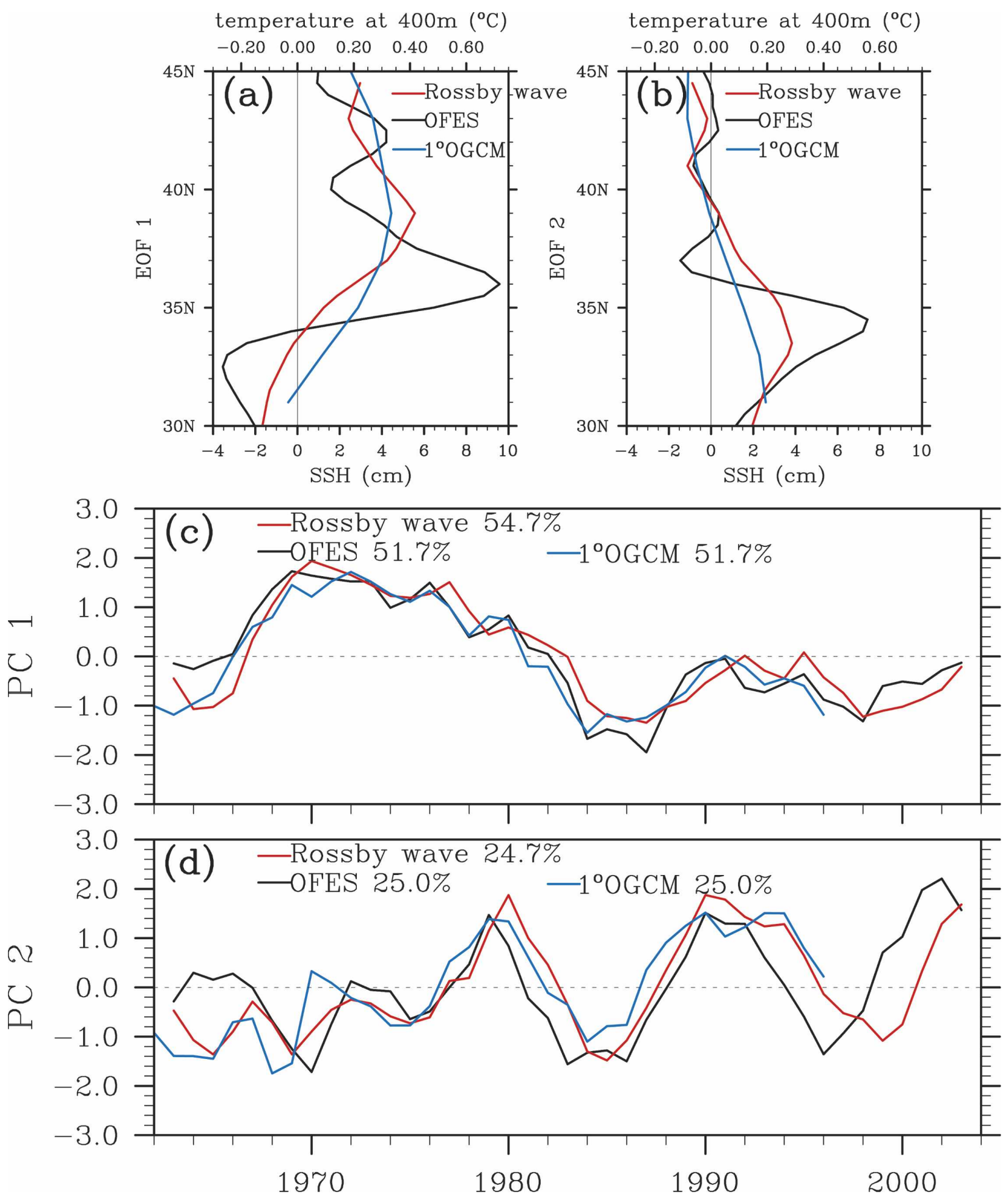

FIG. 7. Meridional EOF modes of the annual- and zonal-mean OFES SSH (black curve), SSH hindcasted with a linear Rossby wave model (red curve), and 400-m temperature simulated with $1^{\circ} \times 1^{\circ}$ OGCM (blue curve): (a) EOF-1, (b) EOF-2, (c) PC-1, and (d) PC-2. 
OFES modes each feature a sharp peak near the mean KE front, the Rossby wave modes display a rather broad meridional structure reflecting large-scale wind forcing. The EOF-1 for the linear model displays a broad peak at $39^{\circ} \mathrm{N}$ while the sharp peak of the OFES EOF-1 is displaced to the south at $36^{\circ} \mathrm{N}$. Although the EOF-2 for the linear model and that for OFES both peak around $33^{\circ}-34^{\circ} \mathrm{N}$, the former has much broader peak than the latter as is the case for the EOF-1. The agreement in time series between the linear model and OFES suggests that wind-forced Rossby waves are an important mechanism for KE variability, but their disagreement in spatial structure of variability indicates that the interaction with the KE jet is important as well.

In Eq. (3), SSH variability is caused by local wind forcing and the westward propagation of remotely forced Rossby waves. We now investigate the effect of Rossby wave propagation by setting $c_{R}=0$ and deriving the EOFs of zonal-mean SSH driven by the local forcing. In this local forcing model, EOF-1 explains more than $90 \%$ of the total variance and is represented by a trend (not shown), and its PC-1 does not display the sudden jump in the early 1980s as in the OFES hindcast and observations. Thus, the Rossby wave propagation is key to reproducing the temporal variability of the KOE region.

Figure 7 also compares with the hindcast by a $1^{\circ}$ by $1^{\circ}$ resolution OGCM of Xie et al. (2000; dotted curves), for which temperatures at 400-m depth are employed for the comparison as a proxy of SSH. Both the space and time structures of this coarse-resolution OGCM hindcast closely resemble the linear Rossby wave model hindcast. ${ }^{3}$ Thus, the Rossby wave dynamics explain quite well noneddy-resolving OGCM results reported in the literature but fail to reproduce the narrow modal structure in the OFES and T/P observations. Recently, Yasuda and Sakurai (2006) analyzed interdecadal variability of $\mathrm{SSH}$ simulated in their $1^{\circ}$ resolution OGCM. They carried out an EOF analysis over a domain near Japan, and their first two EOFs have similar spatiotemporal structures to those found in our linear Rossby wave model. Yasuda and Sakurai (2006) reported that their leading PCs are in good agreement with tide gauge observations along the Japanese coast.

\footnotetext{
${ }^{3}$ Sensitivity experiments show that the spatial structure of the linear Rossby wave model hindcast depends on the damping coefficient [ $\varepsilon$ in Eq. (3)]; the larger the damping, the smoother the meridional structure of the EOFs (not shown). The slightly broader structure of the EOFs based on the coarse-resolution OGCM than that based on the linear Rossby wave is presumably due to the difference in the effective damping between the two.
}

\section{b. Large-versus frontal-scale variability}

The success of the linear model in reproducing the PCs of KE variability indicates the importance of Rossby wave adjustment. Here we divide the SSH anomaly field into large (meridionally broadscale) and frontal (small scale) components and examine how well the linear Rossby wave model explains the broadscale component. Specifically, we extract the broadscale component of SSH variability by applying a $10^{\circ}$ running mean in the meridional direction. The residual is defined as the small-scale component. This is consistent with Nakano et al. (2006, manuscript submitted to Dyn. Atmos. Ocean) who considered the mean Kuroshio Extension system as a superposition of the Sverdrup flow, a jet, and recirculation.

First, we examine SSH changes associated with the first EOF mode (blue curve in Fig. 6b). The PC-1 time series represents the transition between two quasisteady epochs: the preshift (1968-80) and postshift (1984-96) periods. We construct the epoch averages of SSH for the two periods and their differences, the latter of which are dominated by the first mode since the epoch averages of the PC-2 of the KE frontal modes are nearly zero. The unfiltered OFES SSH fields averaged over the preshift and postshift periods are shown by the black contours in Figs. 8a,b, respectively. In OFES, the KE jet shifts southward and intensifies from the former to the latter epoch, consistent with the EOF-1 pattern. The KE and Oyashio Extension are more clearly separated in the post- than in the preshift epoch. The broadscale component of the difference field in OFES (Fig. 8c, shaded) represents the spinup of both the subtropical and subpolar gyres, in broad agreement with the linear Rossby wave model (Fig. 8d, shaded, pattern correlation coefficient $=0.67$ ). This agreement is consistent with results from previous studies showing that the coarse-resolution OGCM simulations of the 1976/77 regime shift compare well with the coarse-resolution observations (Miller et al. 1998; Xie et al. 2000; Seager et al. 2001).

The small, frontal-scale component of the SSH difference features zonally elongated, meridonally tight recirculations along the mean fronts (Fig. 8e, shaded). In particular, a negative SSH difference band at $34^{\circ}-$ $37^{\circ} \mathrm{N}$, along with a positive SSH band to the south at $33^{\circ}-34^{\circ} \mathrm{N}$, gives rise to a southward shift and eastward acceleration of the KE jet. This result agrees with the view that large-scale Rossby waves can induce the nonlinear adjustment of recirculations both north and south of the KE front (Taguchi et al. 2005).

Now let us examine the second EOF mode in OFES. As PC-2 displays a quasi-decadal oscillation (Fig. 4e), 
(a) OFES unfiltered (1968-80)

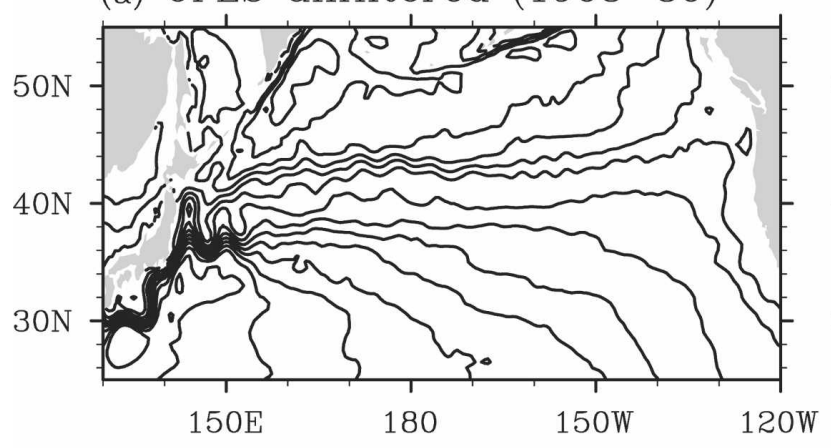

(c) OFES large scale

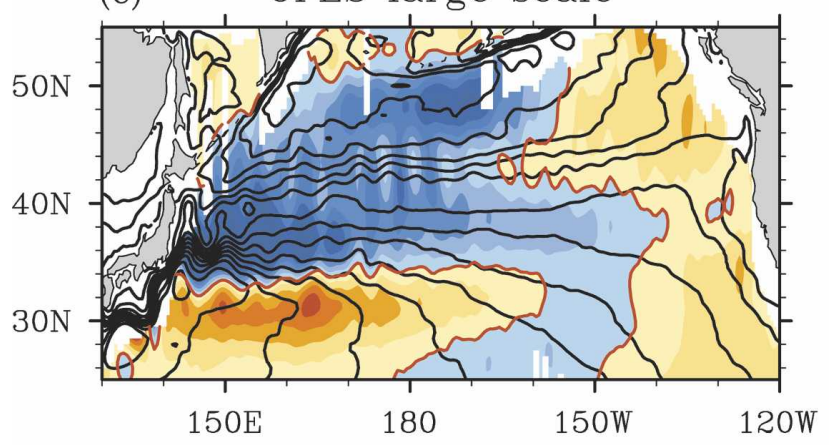

(b) OFES unfiltered (1984-96)

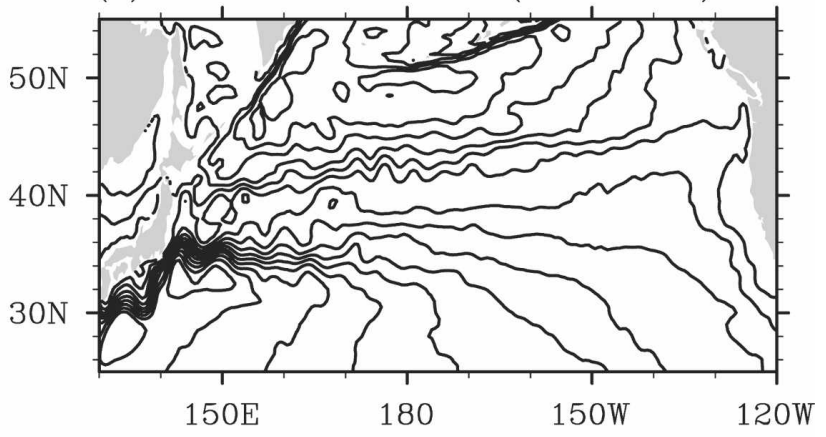

(d) Rossby wave

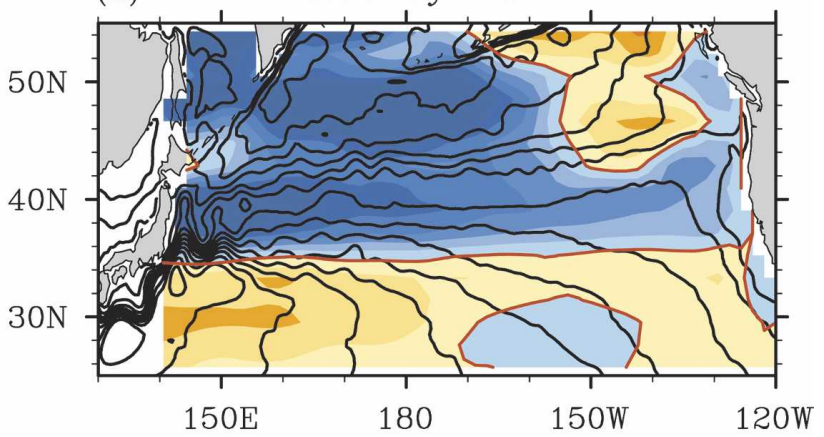

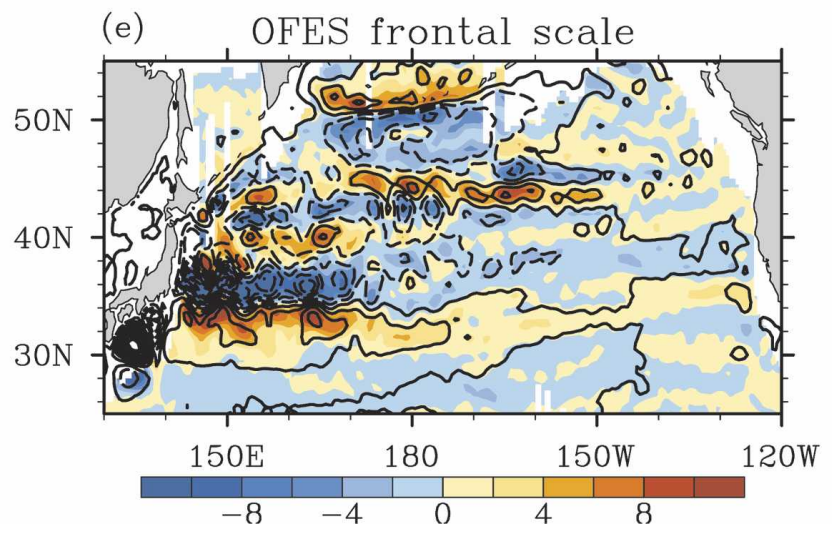

FIG. 8. SSH change in the North Pacific associated with the PC-1 of KE variability. Total SSH (at contour intervals of $10 \mathrm{~cm}$ ) averaged for (a) the preshift period of 1968-80, and (b) the postshift period of 1984-96. (c) Broadscale component of the post- minus preshift difference in OFES SSH (color shaded in $\mathrm{cm}$ ). Unfiltered OFES SSH averaged for both periods is superposed with black contours (at intervals of $10 \mathrm{~cm}$ ). (d) Same as in (c), but for SSH anomalies from the Rossby wave model (shaded). (e) Same as in (c), but for frontal-scale SSH (shaded). Black contours designate differences in the unfiltered OFES SSH between the two periods with contour intervals of $5 \mathrm{~cm}$.

we extract the associated SSH evolution by taking the lagged regression upon PC-2. Prior to calculating the regression, a 3-yr running mean is applied to remove mesoscale eddy variability in the SSH field (Fig. 9). The evolution of the broadscale component of the SSH regression in OFES (left panels) closely resembles the linear model solution (middle panels, pattern correlation coefficient $=0.41,0.61,0.64,0.47,0.55$ at lag -6 , $-3,0,3$, and 6 , respectively). The transient Rossby waves display tilted phase lines consistent with the latitudinal-dependent phase speed of the Rossby wave (Qiu 2003). At lag -6 yr, much of the northwestern Pacific from the KE to the subpolar region is occupied by positive SSH anomalies, whereas the eastern subtropics is occupied by negative SSH anomalies. By lag 0 , the southwestern tip of the negative $\mathrm{SSH}$ band reaches the Japanese coast, and replaces the previous positive SSH anomalies in the KE region. This is fol- 

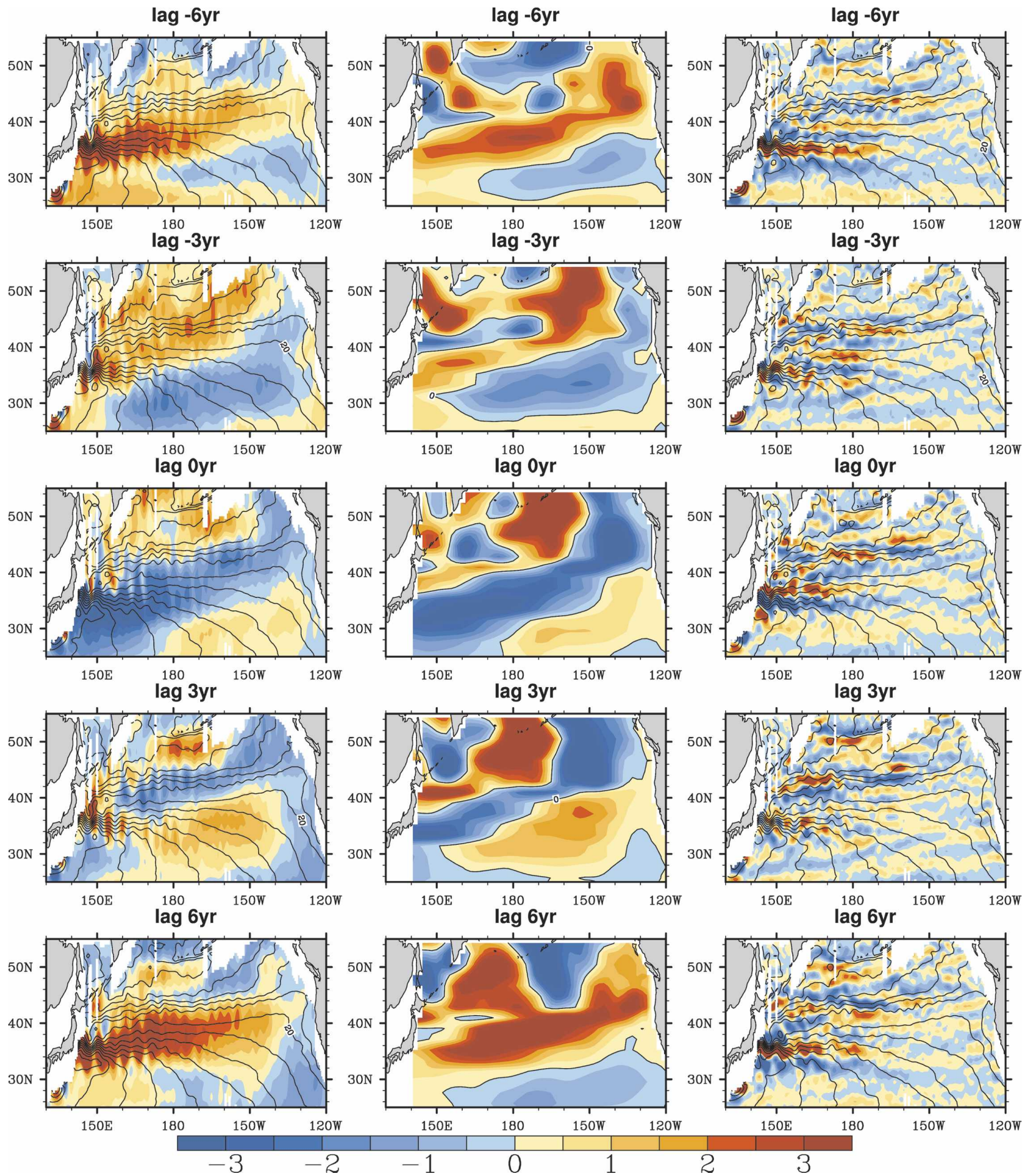

FIG. 9. Lagged regression coefficient of (shaded in left) broadscale and (shaded in right) frontal-scale SSH anomalies onto the 3-yr low-passed PC-2. Superimposed is the mean SSH plus regression coefficient. Contour intervals are $10 \mathrm{~cm}$. Positive lag (in yr) means that the SSH fields lag behind PC-2. (middle) Same as in (left), but for the SSH in the Rossby wave model.

lowed by growing positive anomalies in the eastern subtropics, which propagate westward and arrive at the western boundary at lag $6 \mathrm{yr}$.

The frontal-scale component of the SSH regression field (right panels in Fig. 9) again displays a pair of zonally elongated recirculations with the KE front in between, giving rise to the intensification/weakening of the eastward jet. This pair of anomalous recirculations 
alters the sign from lag -6 to 0 , and again from lag 0 to $6 \mathrm{yr}$. This indicates that the frontal-scale recirculation adjustments to the large-scale environmental changes are initiated by the arrival of Rossby waves.

\section{c. Intrinsic variability}

The western boundary extension jet and the recirculations display low-frequency variability in the absence of wind forcing variability (Jiang et al. 1995; McCalpin and Haidvogel 1996; Dewar 2003; Hogg et al. 2005). This section examines the variability in the 48-yr climatological run, which is forced with the monthly climatological wind stress and buoyancy flux. The initial conditions are the same between the OFES hindcast and the climatological run. Figure 10 compares the interannual SSH standard deviation between the two runs. Annual-mean anomalies are used in standard deviation calculation to suppress mesoscale eddies. Interestingly, the standard deviation is comparable in magnitude and similar in spatial distribution between the two runs (Fig. 1b versus 10a). In both runs, high SSH variability follows the meandering mean KE jet, the Oyashio Extension, and the western boundary. The standard deviation in the climatological run is about $10 \mathrm{~cm}$ along the Oyashio Extension and $20 \mathrm{~cm}$ along the KE. The ratio of the SSH standard deviation (the climatological to the hindcast run; Fig. 10b, color shaded) generally exceeds 0.7 over the most of the analysis domain. Interestingly, this ratio reaches a meridional maximum of about 1.0 around $39^{\circ}-42^{\circ} \mathrm{N}$ between the $\mathrm{KE}$ and Oyashio Extension, which imprints on the EOF modal structure. Note that, while the hindcast run is forced by the atmospheric daily data, the climatological run forced by monthly data still reproduces a comparable amount of the variability. This indicates that the highfrequency forcing is not a major factor to induce the intrinsic variability.

The EOF analysis is applied to the annual-mean SSH anomalies zonally averaged at $142^{\circ} \mathrm{E}-180^{\circ}$ from the climatological forcing run. The leading modes (Figs. $11 \mathrm{a}, \mathrm{b}$, solid curves) resemble those for the hindcast near the KE, representing the meridional shift and intensification of the jet, respectively. Away from the KE, however, $\mathrm{EOF}_{\mathrm{H}}$ and $\mathrm{EOF}_{\mathrm{C}}$ modes are considerably different. Here subscripts " $\mathrm{H}$ " and " $\mathrm{C}$ " denote the hindcast and climatological runs, respectively. South of the Oyashio Extension at $39^{\circ}-40^{\circ} \mathrm{N}, \mathrm{EOF}_{\mathrm{H}^{-1}}$ is at a local minimum but still positive (Fig. 7a) while $\mathrm{EOF}_{\mathrm{C}}-1$ is at its negative extreme. In the recirculation south of the $\mathrm{KE}$ at $32^{\circ} \mathrm{N}, \mathrm{EOF}_{\mathrm{H}^{-}}-2$ is positive (Fig. $7 \mathrm{~b}$ ) while $\mathrm{EOF}_{\mathrm{C}}-2$ is at the negative extreme.

We apply the same EOF analysis to the meridionally high-pass-filtered SSH anomalies of the hindcast run.
The leading EOF modes of frontal-scale variability in the hindcast bear a remarkable resemblance to those in the climatological run (Figs. 11a,b), except the second EOF that differs in phase near the Oyashio Extension north of $39^{\circ} \mathrm{N}$, presumably due to the difference in the mean flow structures between the hindcast and the climatological runs (Fig. 11c). This suggests that $\mathrm{EOF}_{\mathrm{HF}}$ modes are basically the intrinsic modes of the Kuroshio Extension and the recirculation to the south as captured in the climatological run. (Here subscript " $F$ " denotes the frontal-scale variability in the hindcast.) Indeed, the simple superposition of the $\mathrm{EOF}_{\mathrm{R}}$ and $\mathrm{EOF}_{\mathrm{C}}$ modes reproduces the $\mathrm{EOF}_{\mathrm{H}}$ modes quite well (Fig. 12, subscript " $\mathrm{R}$ " denotes the linear Rossby wave model).

Figure 13 compares the PCs of broad- and frontalscale variability, which are obtained by applying the EOF analysis separately to the meridionally low- and high-pass-filtered anomalies of the SSH hindcast. The two sets of PCs are nearly identical. Our analysis in this section suggests the following scenario: basin-scale wind variability excites broadscale Rossby waves, which propagate westward, triggering intrinsic modes of the KE jet and reorganizing SSH variability in space.

In the climatological run, the intrinsic variance of the annual- and zonal-mean $\left(142^{\circ} \mathrm{E}-180^{\circ}\right) \mathrm{SSH}$ anomalies integrated over $30^{\circ}-45^{\circ} \mathrm{N}$ amounts to $46.5 \%$ of the total variance in the hindcast run. Even free of interannual variability in wind forcing, the leading PCs in the climatological run are dominated by variability on decadal time scales (Fig. 11d). In the OFES hindcast, however, the first two EOF modes, whose time series are reproducible with a linear model of wind-forced Rossby waves, explain $76.7 \%$ of the total variance (Fig. 7). The residual variance $(23.3 \%)$ is only about half the intrinsic variance in the climatological run. Thus, wind-forced Rossby waves act as a pacemaker regulating the intrinsic modes of variability. Such pacemaking phenomena are commonly observed in nonlinear systems.

Other than the arrival of the Rossby waves, surface heat flux, if it drives SST anomalies in the KOE region, could contribute to the organization of the frontal-scale variability in the OFES hindcast and its phase locking to the observation by constraining the upper-ocean density gradient. However, Nonaka et al. (2006) reported that the heat flux anomalies in the OFES hindcast damp, rather than force, the SST anomalies along the fronts in the KOE region on the decadal time scale, indicative of a minor role of the thermal forcing in regulating the frontal variability. It is still of interest to conduct a separate experiment without the surface thermal constraints (e.g., an OFES hindcast with monthly climatological heat flux or a regional coupled oceanatmosphere model experiment) to clarify the point. 


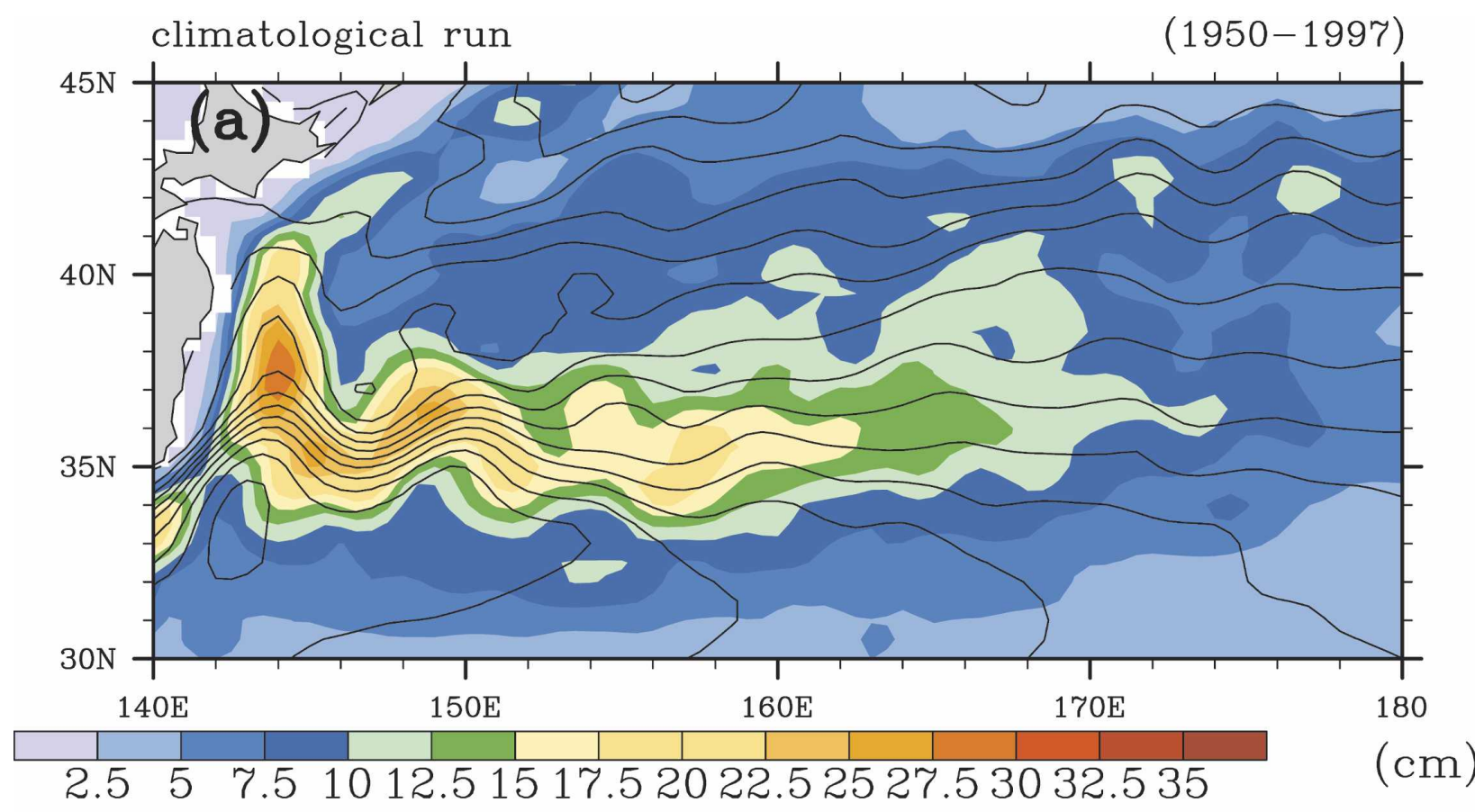

climatological/hindcast

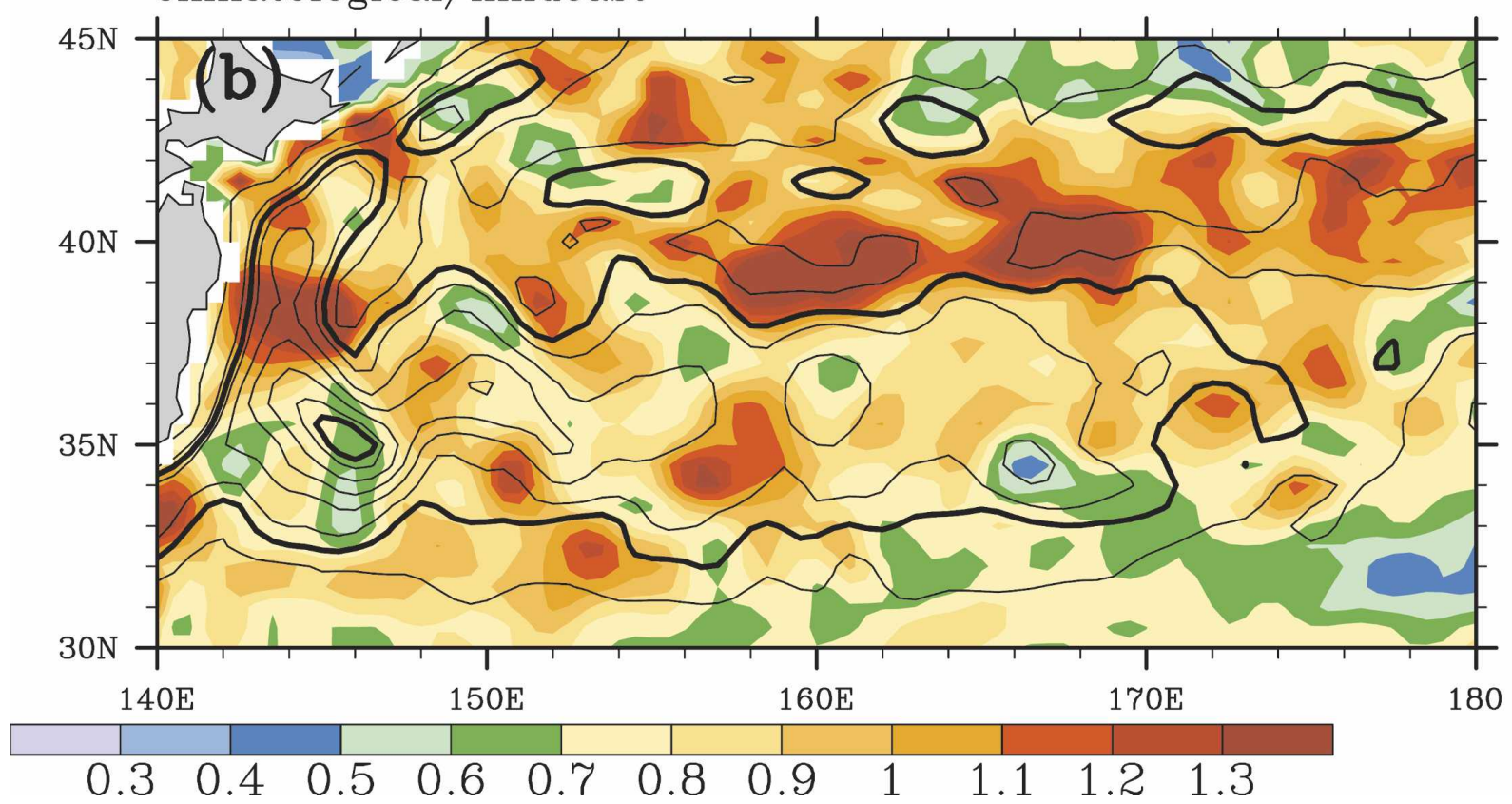

FIG. 10. (a) Climatological-mean SSH (contours at intervals of $10 \mathrm{~cm}$ ) and standard deviation of annual-mean SSH anomalies (shading in $\mathrm{cm}$ ) in the OFES climatological run for 48 yr. (b) Ratio (color shaded) of SSH standard deviation (climatological to the hindcast run) for 1962-2003, and standard deviation in the hindcast (contours at intervals of $2.5 \mathrm{~cm}$ with the 10-cm contour thickened).

\section{Discussion}

\section{a. Origin of intrinsic modes}

Previous double-gyre studies using simpler, idealized models show that nonlinear recirculations gyres display low-frequency variability under steady wind forcing. McCalpin and Haidvogel (1996) show that in a 1.5-layer reduced-gravity model, the ocean circulation experiences transitions between high and low energy regimes characterized by a strong, zonal-extended extension jet 


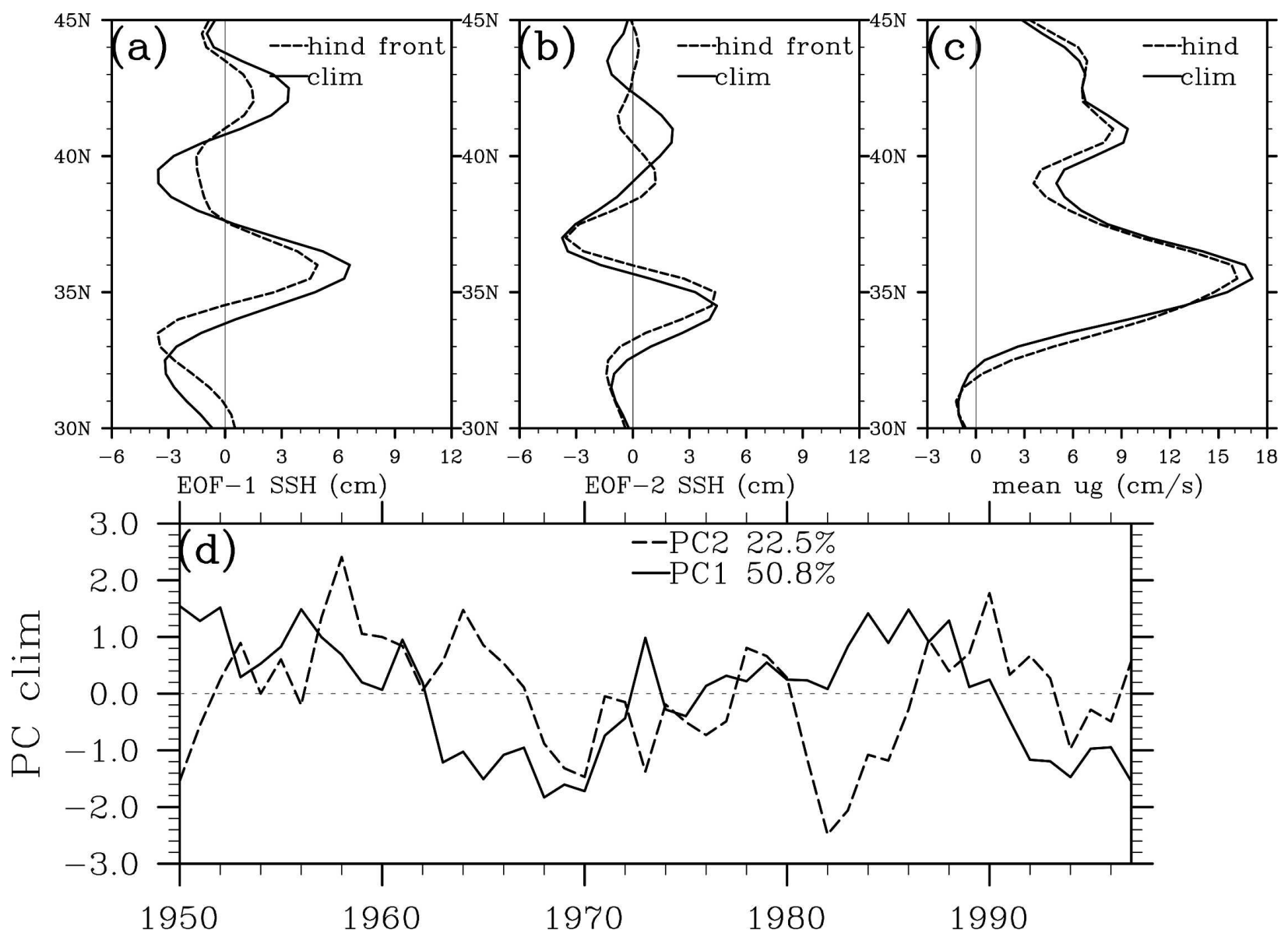

FIG. 11. (a) SSH EOF-1 in the climatological run (solid line), and for frontal-scale variability in the hindcast (dashed). (b) Same as in (a), but for EOF-2. (c) Mean geostrophic zonal velocities averaged over $142^{\circ} \mathrm{E}-180^{\circ}$ in the climatological run (solid line) and the hindcast (dashed). (d) First two PCs in the climatological run.

and a weak, westward-confined one, respectively. Using three-layer quasigeostrophic models, Dewar (2003) and Hogg et al. (2005) report two modes of recirculation variability representing the meridional shift and intensification of the intergyre jet, respectively, much as in OFES. Dewar (2003) shows that the shift mode involves adjustment in the well-mixed potential vorticity $(\mathrm{PV})$ pool in the lower layer and is preferentially excited by wind forcing at decadal and lower frequencies. (Interannual forcing excites a meander mode instead.) While Dewar (2003) suggests the eddy mixing of PV in the lower layers as the mechanism for low-frequency variability, our analysis of the OFES hindcast indicates the importance of wind-forced Rossby waves. In OFES, we do not detect appreciable delays in the frontal-scale PCs behind either of the PCs from the linear Rossby wave model. Taguchi et al. (2005) suggest that the rapid frontal-scale adjustment is accomplished by changes in offshore PV advection from the western boundary as wind-induced baroclinic Rossby waves arrive from the east. As Taguchi et al. (2005) point out, the development of a diagnostic tool for the interaction of the inertial jet, PV advection, recirculation, and mesoscale eddies is in urgent need to shed light on the mechanism for frontal-scale adjustment.

\section{b. Prediction experiment}

The slow propagation of baroclinic Rossby waves is a source of predictability. We perform a prediction run, in which the OFES is initialized with the hindcast field on 1 January 2000 and integrated forward under monthly climatological atmospheric forcing. We project the zonal-mean SSH anomalies in the prediction run onto the first EOF mode in the hindcast run for the T/P era (i.e., $\mathrm{EOF}_{\mathrm{TP}}-1$; Fig. 14). The resultant time series (blue curve) closely follows the OFES hindcast as well as $\mathrm{T} / \mathrm{P}$ observations for up to 9 months, including an initial decrease and the subsequent increase in PC-1. The relatively short lead time may suggest the importance of the local and contemporaneous wind forcing 

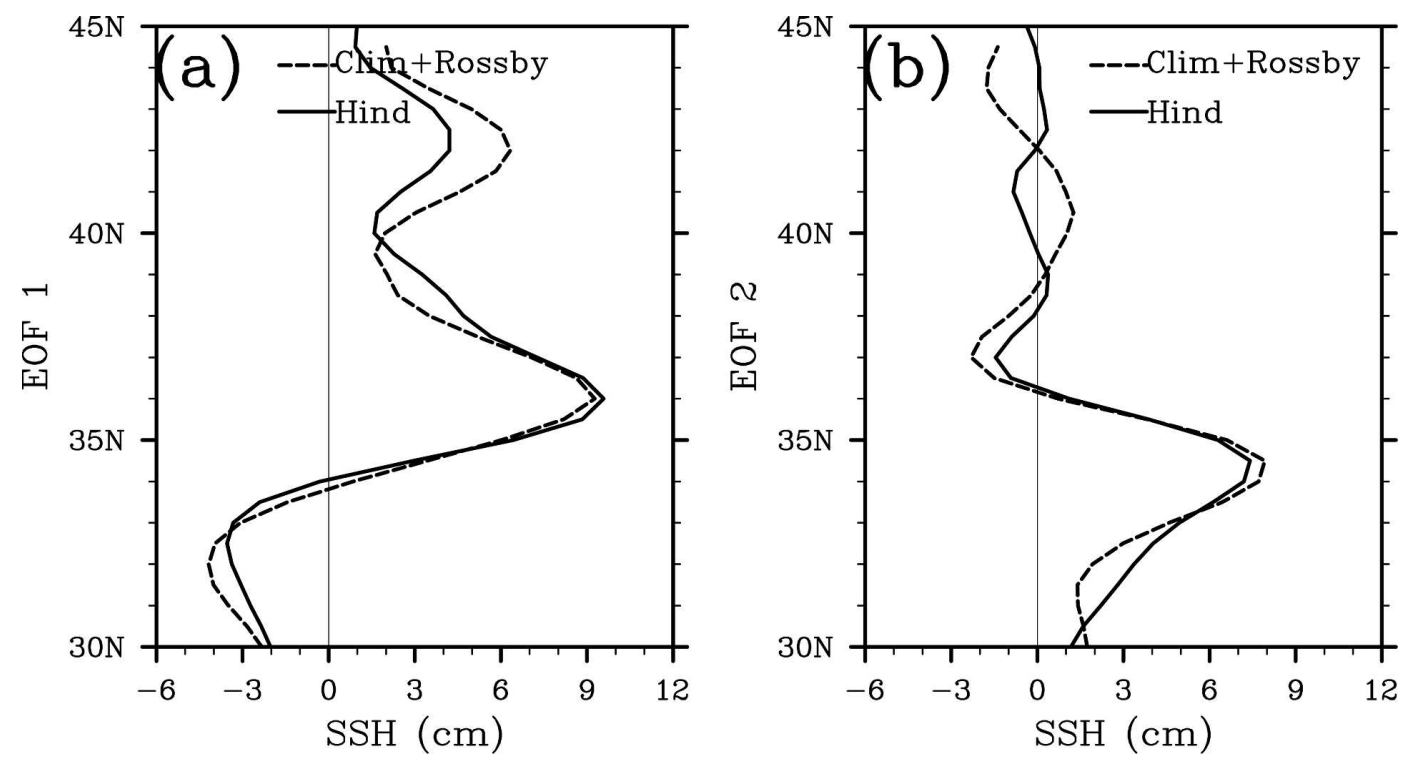

FIG. 12. (a) First and (b) second $\mathrm{EOF}_{\mathrm{H}}$ (solid line; same as in Fig. 7a, solid line), along with the sum of the corresponding $\mathrm{EOF}_{\mathrm{R}}$ and $\mathrm{EOF}_{\mathrm{C}}$ (dashed). Subscripts $\mathrm{R}, \mathrm{C}$, and $\mathrm{H}$ denote the linear Rossby wave model, the climatological run, and the hindcast run, respectively.

for the SSH field near the western boundary or may simply represent a single realization of possible multiple solutions. The costs of running the full OFES prohibit the use of a large ensemble for a quantitative determination of useful lead time. This preliminary prediction result is consistent with Schneider and Miller (2001), who use a one-dimendional Rossby wave model. Our use of the full OFES, however, allows the prediction of the meridional position and intensity of the KE front, information useful for the prediction and management of marine ecosystems and fishery resources near Japan (Sasai et al. 2005; Noto and Yasuda 2003).

Analyzing a high-resolution coupled ocean-atmospheric model projection of future climate, Sakamoto et al. (2005) suggest that increased atmospheric $\mathrm{CO}_{2}$ concentration would cause an acceleration of the KE Current in response to basinwide wind stress changes and recirculation adjustment. The wind control of frontal-scale adjustment demonstrated here can help infer changes in the KE jet in global warming scenario runs in coarse-resolution models by using projected wind changes, following the methodology in section 4 .

\section{Summary}

We have analyzed a multidecadal hindcast by the high-resolution, eddy-resolving OFES. Low-frequency variability in SSH is concentrated on the KE front, and may be characterized by two EOF modes. The first mode represents a southward shift and to a lesser degree, an acceleration of the KE jet in the early 1980s that separates two quasi-steady periods before and after. The jump lags the wind shift associated with the Aleutian low regime shift of 1976/77 by $4 \mathrm{yr}$ (Nitta and Yamada 1989; Miller et al. 1994). This time delay is consistent with the baroclinic Rossby wave adjustment to wind change (Miller et al. 1998; Deser et al. 1999; Xie et al. 2000; Seager et al. 2001). The second EOF mode represents intensity variations in the KE jet and displays quasi-decadal oscillations. These OFES modes compare remarkably well with satellite altimeter and XBT observations in both spatial structure and temporal evolution, rendering the OFES hindcast a valuable dataset to study variability in other inertial jets (e.g., the Gulf Stream) and its mechanisms.

The spatial structure of EOF modes in OFES and satellite altimeter observations is narrowly trapped along the KE jet, in contrast with that of the linear Rossby wave response to broadscale wind forcing. But paradoxically, the linear Rossby wave model reproduces quite well the leading principal components in the OFES hindcast and satellite observations. As a solution to this paradox, we suggest that the broadscale Rossby waves trigger frontal-scale adjustment upon arriving in the KE region in the northwestern Pacific east of Japan. We separate OFES variability into meridionally broad- and frontal-scale components. The broadscale component indeed resembles the linear Rossby wave response to wind variability while the frontal- 


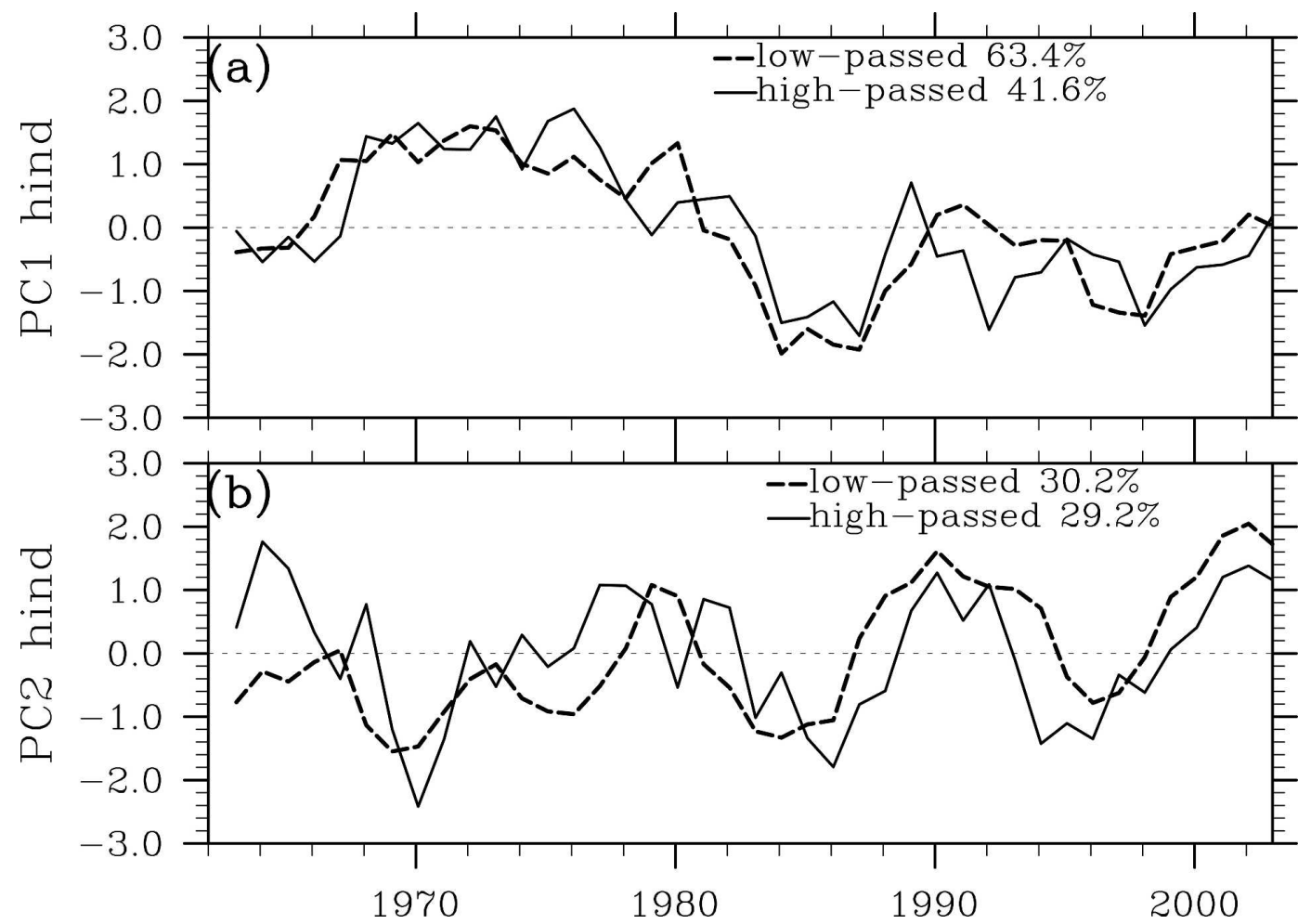

FIG. 13. (a) PC-1 and (b) PC-2 for the broadscale (solid) and frontal-scale (dashed) SSH variability in the hindcast.

scale variability bears a remarkable similarity to intrinsic modes of the climatological run in spatial structure but is in sync with the broadscale component in time, consistent with the above hypothesis. Free of wind changes in the climatological run, the intrinsic modes of variability feature meridionally narrow, zonally elon- gated recirculation/jet structures near the $\mathrm{KE}$ and Oyashio Extension jets in space, and display decadal time scales. Regarding the internal variability versus wind forcing debate between the two schools as discussed in the introduction, our results suggest that the wind-forced Rossby waves control the time series of the

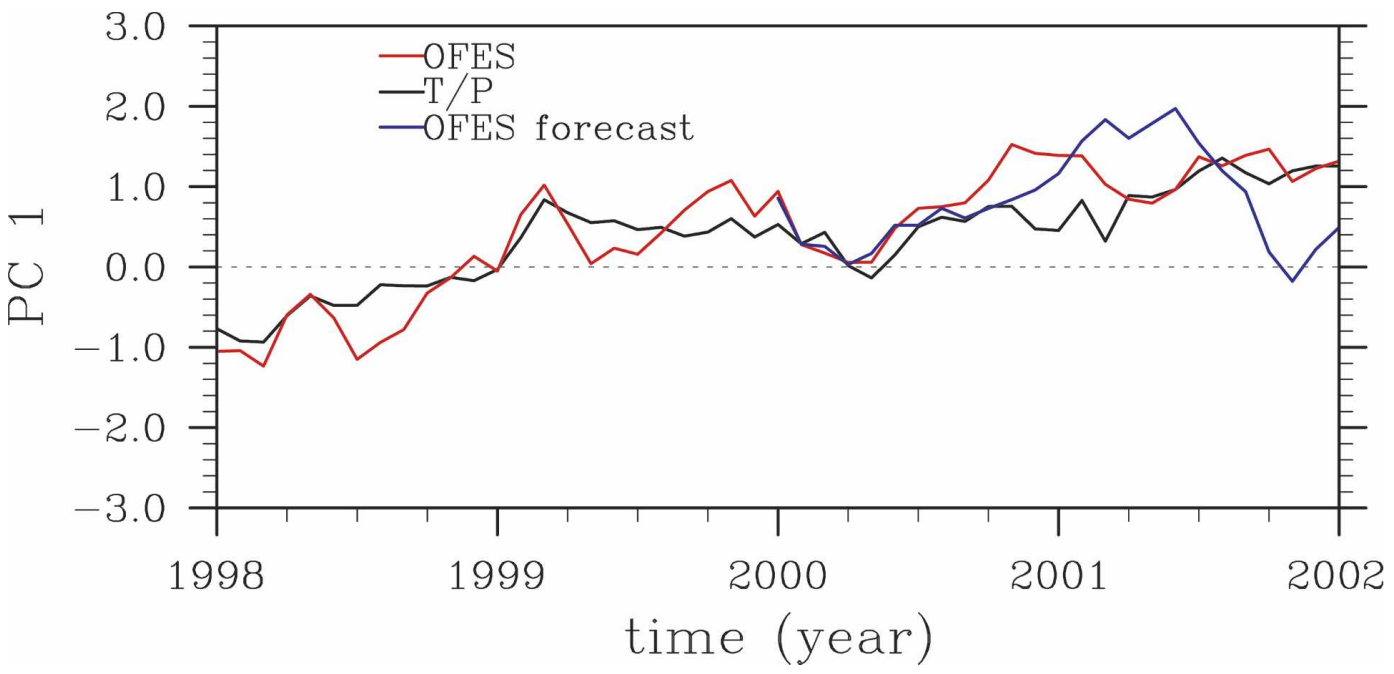

FIG. 14. OFES prediction from January 2000 (blue), obtained by projecting the zonally averaged SSH anomalies in the prediction run onto the $\mathrm{EOF}_{\mathrm{TP}}-1$. Superimposed as validation are PCs-1 for the OFES hindcast (red) and satellite altimeter observations (black). 
KE variability while internal modes of variability are key to the spatial reorganization of wind-forced variability in the recirculation/inertial jet system.

Subsurface variability exerts a strong influence on SST in the KE and Oyashio Extension (Latif and Barnett 1994; Xie et al. 2000; Qiu 2000; Seager et al. 2001; Schneider et al. 2002; Nonaka et al. 2006). Recent satellite observations show that SST variability in the region affects local wind and clouds through the atmospheric boundary layer adjustment (Nonaka and Xie 2003; Xie 2004; Tokinaga et al. 2006). An outstanding question is whether, and how, oceanic low-frequency variability found in this study induces a large-scale response in the atmosphere. In this regard, Tanimoto et al. (2003) reported systematic changes in the stormtrack activity and its feedback forcing onto the Pacific North American pattern associated with decadal SST anomalies in the KOE region, a finding consistent with a hypothesis that oceanic fronts maintain baroclinicity in the atmospheric boundary layer and thereby influence storm-track activity (Inatsu et al. 2003; Nakamura et al. 2004). To further explore this possible large-scale atmospheric adjustment, numerical experiments using high-resolution atmospheric models (Ohfuchi et al. 2004, 2005; Taguchi 2006) are ongoing. Although this study focuses on KE variability, it is also important to study Oyashio Extension variability, which is largely out of sync with the former and accompany larger SST anomalies that may influence the atmosphere (Nonaka et al. 2006). Another important line of research is to extend our study of physical variability to ecosystem response and explore its predictability.

Acknowledgments. We wish to thank B. Qiu for helpful discussions; J. Hafner and APDRC for archiving satellite data and hindcast output; and H. Nakamura, Y. Tanimoto, and two anonymous reviewers for their careful reading that helped improve the earlier version of this manuscript. This work is supported by the Japan Agency for Marine-Earth Science and Technology (JAMSTEC), National Science Foundation (NSF) Grants ATM04-54390 and OCE05-50233, the National Aeronautics and Space Administration (NASA) Grant NA17RJ1231, and the U.S. Department of Energy (DOE) Office of Science Grant DE-FG02-04ER63862. The views expressed herein are those of the authors and do not necessarily reflect the view of JAMSTEC, NSF, DOE, NASA, or any of their subagencies.

\section{REFERENCES}

Boyer, T. P., S. Levitus, J. I. Antonov, M. E. Conkright, T. O'Brien, and C. Stephens, 1998a: Salinity of the Atlantic
Ocean. Vol. 4, World Ocean Atlas 1998, NOAA Atlas NESDIS 30, 166 pp.

,,,,,----- and,$- 1998 \mathrm{~b}$ : Salinity of the Pacific Ocean. Vol. 5, World Ocean Atlas 1998, NOAA Atlas NESDIS 30, $166 \mathrm{pp}$.

linity of the Indian Ocean. Vol. 6, World Ocean Atlas 1998, NOAA Atlas NESDIS 30, 166 pp.

Cessi, P. R., G. Ierley, and W. R. Young, 1987: A model of inertial recirculation driven by potential vorticity anomalies. J. Phys. Oceanogr., 17, 1640-1652.

Deser, C., M. A. Alexander, and M. S. Timlin, 1999: Evidence for a wind-driven intensification of the Kuroshio Current Extension from the 1970s to the 1980s. J. Climate, 12, 1697-1706.

Dewar, W. K., 2003: Nonlinear midlatitude ocean adjustment. $J$. Phys. Oceanogr., 33, 1057-1082.

Dijkstra, H. A., and M. Ghil, 2005: Low-frequency variability of the ocean circulation: A dynamical systems approach. Rev. Geophys., 43, RG3002, doi:10.1029/2002RG000122.

Ducet, N., P.-Y. LeTraon, and G. Reverdin, 2000: Global high resolution mapping of ocean circulation from TOPEX/ Poseidon and ERS-1/2. J. Geophys. Res., 105, 19 477-19 498.

Fyfe, J. C., and D. J. Lorenz, 2005: Characterizing midlatitude jet variability: Lessons from a simple GCM. J. Climate, 18, 34003404.

Hogg, A. M., P. D. Killworth, J. R. Blundell, and W. K. Dewar, 2005: Mechanisms of decadal variability of the wind-driven ocean circulation. J. Phys. Oceanogr., 35, 512-531.

Inatsu, M., H. Mukougawa, and S.-P. Xie, 2003: Atmospheric response to zonal variations in midlatitude SST: Transient and stationary eddies and their feedback. J. Climate, 16, 33143329.

Jiang, S., F.-F. Jin, and M. Ghil, 1995: Multiple equilibria, periodic, and aperiodic solutions in a wind-driven, double-gyre, shallow-water model. J. Phys. Oceanogr., 25, 764-786.

Kalnay, E., and Coauthors, 1996: The NCEP/NCAR 40-Year Reanalysis Project. Bull. Amer. Meteor. Soc., 77, 437-471.

Latif, M., and T. P. Barnett, 1994: Causes of decadal climate variability over the North Pacific and North America. Science, 266, 634-637.

Masumoto, Y., and Coauthors, 2004: A fifty-year eddy-resolving simulation of the World Ocean-Preliminary outcomes of OFES (OGCM for the Earth Simulator). J. Earth Simul., 1, $31-52$.

McCalpin, J., and D. B. Haidvogel, 1996: Phenomenology of the low-frequency variability in a reduced-gravity, quasigeostrophic double-gyre model. J. Phys. Oceanogr., 26, 739-752.

Miller, A., D. Cayan, T. P. Barnett, N. E. Graham, and J. M. Oberhuber, 1994: Interdecadal variability of the Pacific Ocean: Model response to observed heat flux and wind stress anomalies. Climate Dyn., 9, 287-302.

_ _ _ , and W. White, 1998: A westward-intensified decadal change in the North Pacific thermocline and gyre-scale circulation. J. Climate, 11, 3112-3127.

Nakamura, H., T. Sampe, Y. Tanimoto, and A. Shimpo, 2004: Observed associations among storm tracks, jet streams, and midlatitude oceanic fronts. Earth Climate: The Ocean-Atmosphere Interaction, Geophys. Monogr., Vol. 147, Amer. Geophys. Union, 329-345.

Niiler, P. P., N. A. Maximenko, and J. C. McWilliams, 2003: Dynamically balanced absolute sea level of the global ocean derived from near-surface velocity observations. Geophys. Res. Lett., 30, 2164, doi:10.1029/2003GL018628. 
Nitta, T., and S. Yamada, 1989: Recent warming of tropical sea surface temperature and its relationship to the Northern Hemisphere circulation. J. Meteor. Soc. Japan, 67, 375-383.

Nonaka, M., and S.-P. Xie, 2003: Covariations of sea surface temperature and wind over the Kuroshio and its extension: Evidence for ocean-to-atmospheric feedback. J. Climate, 16, 1404-1413.

- , H. Nakamura, Y. Tanimoto, T. Kagimoto, and H. Sasaki, 2006: Decadal variability in the Kuroshio-Oyashio Extension simulated in an eddy-resolving OGCM. J. Climate, 19, 19701989.

Noto, M., and I. Yasuda, 2003: Empirical biomass model for the Japanese sardine, Sardinops melanostictus, with sea surface temperature in the Kuroshio Extension. Fish. Oceanogr., 12, $1-9$.

Ohfuchi, W., and Coauthors, 2004: 10-km mesh meso-scale resolving simulations of the global atmosphere on the Earth Simulator-Preliminary outcomes of AFES (AGCM for the Earth Simulator). J. Earth Simul., 1, 8-34.

- - H. Sasaki, Y. Masumoto, and H. Nakamura, 2005: Mesoscale resolving simulations of the global atmosphere and ocean on the Earth simulator. Eos, Trans. Amer. Geophys. Union, 86, 45-46.

Pacanowski, R. C., and S. M. Griffies, 1999: MOM 3.0 manual. Tech. Rep. 4, NOAA/Geophysical Fluid Dynamics Laboratory, $680 \mathrm{pp}$.

Pierce, D. W., T. P. Barnett, N. Schneider, R. Saravanan, D. Dommenget, and M. Latif, 2001: The role of ocean dynamics in producing decadal climate variability in the North Pacific. Climate Dyn., 18, 51-70.

Qiu, B., 2000: Interannual variability of the Kuroshio Extension system and its impact on the wintertime SST field. $J$. Phys. Oceanogr., 30, 1486-1502.

_ 2002a: The Kuroshio extension system: Its large-scale variability and role in the midlatitude ocean-atmosphere interaction. J. Oceanogr., 58, 57-75.

, 2002b: Large-scale variability in the midlatitude subtropical and subpolar North Pacific Ocean: Observations and causes. J. Phys. Oceanogr., 32, 353-375.

_ 2003: Kuroshio Extension variability and forcing of the Pacific decadal oscillations: Responses and potential feedback. J. Phys. Oceanogr., 33, 2465-2482.

— Jet, recirculation gyre, and mesoscale eddies on decadal time scales. J. Phys. Oceanogr., 35, 2090-2103.

Qu, T., S.-P. Xie, H. Mitsudera, and A. Ishida, 2002: Subduction of the North Pacific mode waters in a global eddy-resolving GCM. J. Phys. Oceanogr., 32, 746-763.

Sakamoto, T. T., H. Hasumi, M. Ishii, S. Emori, T. Suzuki, T. Nishimura, and A. Sumi, 2005: Responses of the Kuroshio and the Kuroshio Extension to global warming in a highresolution climate model. Geophys. Res. Lett., 32, L14617, doi:10.1029/2005GL023384.

Sasai, Y., A. Ishida, Y. Yamanaka, and H. Sasaki, 2004: Chlorofluorocarbons in a global ocean eddy-resolving OGCM: Pathway and formation of Antarctic Bottom Water. Geophys. Res. Lett., 31, L12305, doi:10.1029/2004GL019895.
, Kawahara, H. Uehara, and Y. Yamanaka, 2005: A global eddy-resolving coupled physical-biological model: Physical influences on a marine ecosystem in the North Pacific. Open International Conference on Modeling and Simulation-OICMS 2005, D. R. C. Hill, V. Barra, and M. K. Troer, Eds., Blaise Pascal University, 129-138.

Sasaki, H., and M. Nonaka, 2006: Far-reaching Hawaiian Lee Countercurrent driven by wind-stress curl induced by warm SST band along the current. Geophys. Res. Lett., 33, L13602, doi:10.1029/2006GL026540.

Schneider, N., and A. Miller, 2001: Predicting western North Pacific Ocean climate. J. Climate, 14, 3997-4002.

- and B. D. Cornuelle, 2005: The forcing of the Pacific decadal oscillation. J. Climate, 18, 4355-4373.

_ A. A. Miller, and D. W. Pierce, 2002: Anatomy of North Pacific decadal variability. J. Climate, 15, 586-605.

Scott, R. B., and B. Qiu, 2003: Predictability of SST in a stochastic climate model and its application to the Kuroshio Extension region. J. Climate, 16, 312-322.

Seager, R., Y. Kushnir, N. H. Naik, M. A. Cane, and J. Miller, 2001: Wind driven shifts in the latitude of the Kuroshion Oyashio Extension and generation of SST anomalies on decadal timescales. J. Climate, 14, 4249-4265.

Taguchi, B., 2006: A modeling study of the Kuroshio Extension: Decadal variability and influence on the atmosphere. Ph.D. thesis, University of Hawaii at Manoa, $97 \mathrm{pp}$.

- S.-P. Xie, H. Mitsudera, and A. Kubokawa, 2005: Response of the Kuroshio Extension to Rossby waves associated with the 1970s climate regime shift in a high-resolution ocean model. J. Climate, 18, 2979-2995.

Tanimoto, Y., H. Nakamura, T. Kagimoto, and S. Yamane, 2003: An active role of extratropical sea surface temperature anomalies in determining anomalous turbulent heat flux. $J$. Geophys. Res., 108, 3304, doi:10.1029/2002JC00175.

Tokinaga, H., and Coauthors, 2006: Atmospheric sounding over the winter Kuroshio Extension: Effect of surface stability on atmospheric boundary layer structure. Geophys. Res. Lett., 33, L04703, doi:10.1029/2005GL025102.

Tomita, T., S.-P. Xie, and M. Nonaka, 2002: Estimates of surface and subsurface forcing for decadal sea surface temperature variability in the mid-latitude North Pacific. J. Meteor. Soc. Japan, 80, 1289-1300.

Trenberth, K. E., and J. W. Hurrell, 1994: Decadal atmosphereocean variations in the Pacific. Climate Dyn., 9, 303-319.

White, W. B., 1995: Design of a global observing system for gyrescale upper ocean temperature variability. Progress in Oceanography, Vol. 36, Pergamon Press, 169-217.

Xie, S.-P., 2004: Satellite observations of cool ocean-atmosphere interaction. Bull. Amer. Meteor. Soc., 85, 195-208.

_ , T. Kunitani, A. Kubokawa, M. Nonaka, and S. Hosoda, 2000: Interdecadal thermocline variability in the North Pacific for 1958-97: A GCM simulation. J. Phys. Oceanogr., 30, 2798-2813.

Yasuda, T., and K. Sakurai, 2006: Interdecadal variability of the sea surface height around Japan. Geophys. Res. Lett., 33, L01605, doi:10.1029/2005GL02490. 